\title{
أثر تغير سعر الصرف على التجارة الخارجية الكلية والزراعية فى مصر
}

\author{
ممدوح البدرى محمد
}

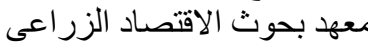

mamdouhelbadry2000@yahoo.com

Received: Jul. 18 , 2017

Accepted: Aug. 21,2017

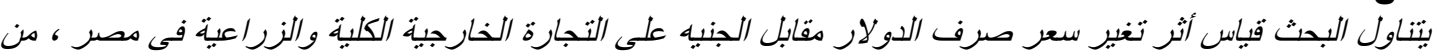

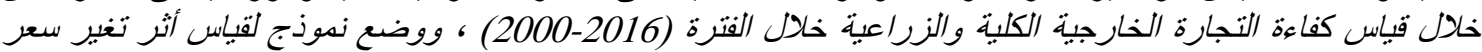

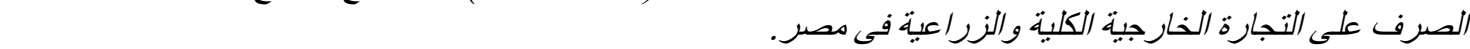

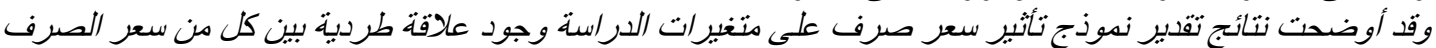

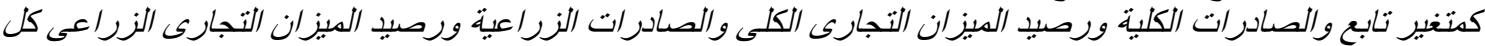

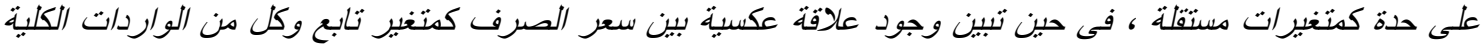
والواردات الزراعية كل على حلة كمتغبيرات مستقلة.

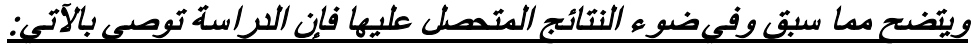

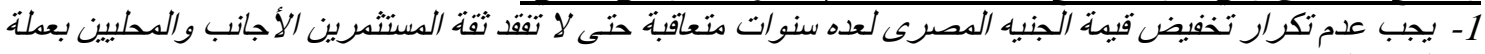
الجنبيه المصرى.

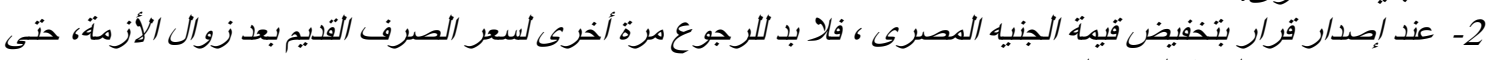

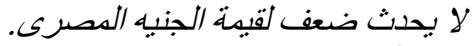

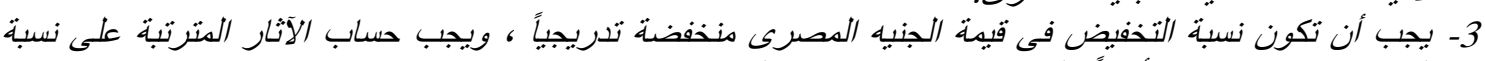

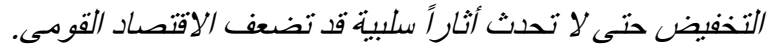

4- ضرورة تقبيم سعر صرف لإن الجنبه الدصرى مقابل العملات الأجنبية الأخرى، أو دول التبادل التجارى (أوروبا وآسيا والصبين) ولبيس على عملة الدولار الأمبيكى فقط. 5- بقترح لتخفيض وليبن العجز في رصبي المبزان التجارى ضرورة رفئ السعار الفائدة على الودائع المصرية ، وترشبي الواردات

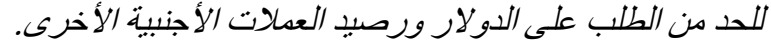

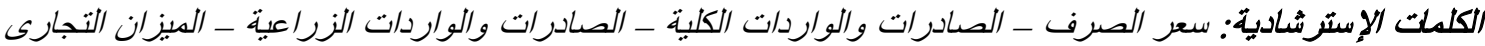

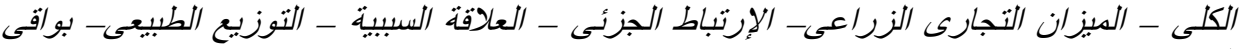

النموزج النمب

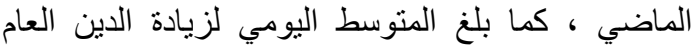

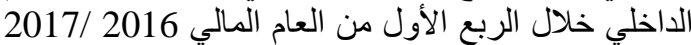

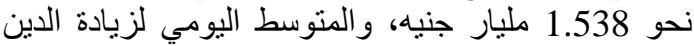

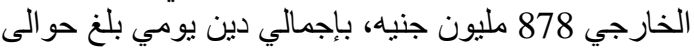

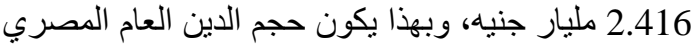

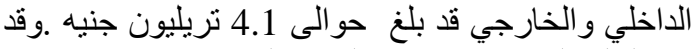

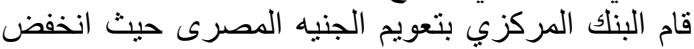

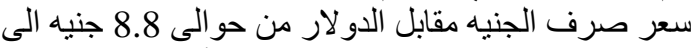

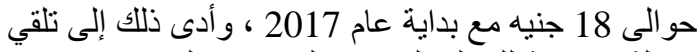

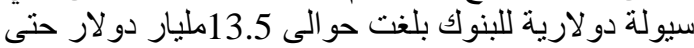

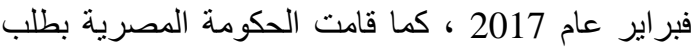

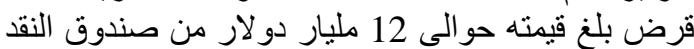

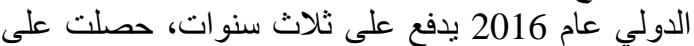

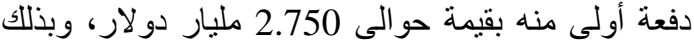
بلغ إجمالى قيمة الديون الخارجية حولية حوالى 60.152 مليار

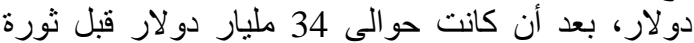

بناير 2011) دولان

(1) -http://www.syrianef.org/?p=4919
مقدمة :

تتعرض بعض : الدول النامية منذ ثمانينات القرن

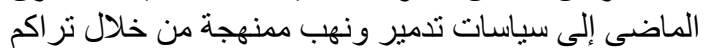

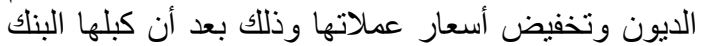

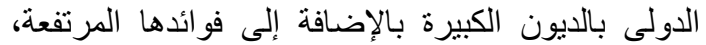

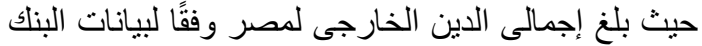
المركزي المصري حوالى المئ 60.152 مليار دو لار في نهاية

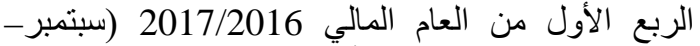
يوليو)، مقارنة بالربع الأخير للعام المالي المالي الماضي

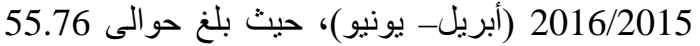

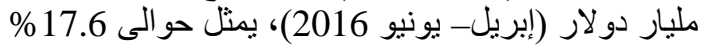

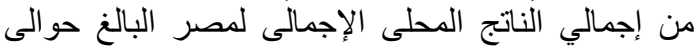
342.8 مليار دو لار عام 2016، في حين بلغ إجمالى فو ائد

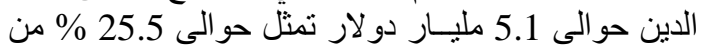

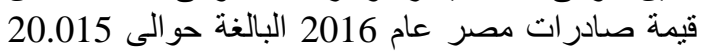

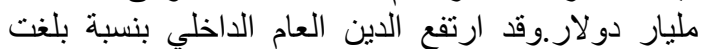

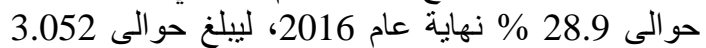

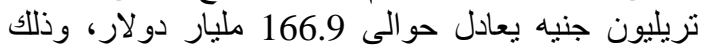
مقابل 2.368 تريليون جنيه خلال نفس الفترة من العام 
مصر تخفيض قيمة الجنيه المصري كمحاولة للخروج من الأزمة الاقتصادية الراهنة إلى اقتصاد السوق، واعطاء دفعة قوية للاقتصاد القومي من خلال استراتيجية زيادة الصادرات والحد من الواردات لإعادة التوازن للميزان التجاري المصري، حيث تلاحظ زيادة قيمة الواردات الكلية من حوالى 58.903 مليار دولار عام 2011 إلى تلى حو الى 76.213 مليار دو لار عام 2016 بنسبة زيادة بلغت حوالى 29.4 \%، في حين تراجعت قيمة الصادر ات الكلية من حوالى 30.528 مليار دولار عام 2011 إلى حوالى تلى 18.705 مليار دولار عام 2016 بنسبة إنخفاض بلغت حو الى 38.7 \% مقارنة بعام 2011، وقد تبين زيادة العجز في الميزان التجارى الكلى من حو الى 28.38 مليار دو لار عام 2011 إلى حوالى 57.51 مليار دولار الثار عام 2016 بنسبة زيادة بلغت حو الى 102.7\% مقارنة بعام 2011 ـ 2011 ملى وقد أدى حدوث نقلبات فى حجم التجارة الخارجية الزراعية المصرية و الميزان التجارى الزر اعى المصرى،

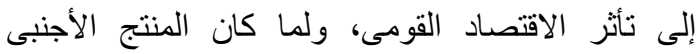
المصدر للسوق المصرية بعتمد فى إنتاجه على عملته المحلية، الأمر الذى جعله ينقل عبء التغير في سعر النقاه الصرف إلى قيمة الواردات من السلع الوسيطة والإستهلاكية وعلى أسعار السلع المصرية النهائية اللمستورد المصرى، الأمر الذى استدعى دراسة أثر تغير

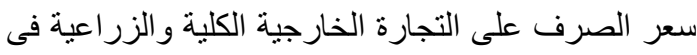

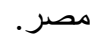

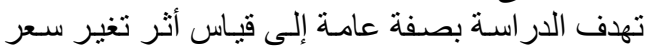

\section{الهُف البحثى:}

الصرف على التجارة الخارجية الكلية و الزر اعية فى مصر تصر

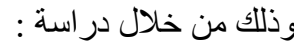

1- نطور سعر الصرف خلال الفترة (2017-2000). 2- تطور إجمالى الصادرات والوراردات الكرات الكلية خلال الفترة (2016-2000) - 2000)

3- نطور الفجوة فى الميزان الكلي خلال الفترة (2000(2016)

4- تطور إجمالى الصادرات والواردات الزراعية خلال الفترة (2016-2000).

5- تطور الفجوة فى الميزان الزراعي خلال الفترة (2016-2000)

6- قياس كفاءة التجارة الخارجية الكلية والزر اعية خلال الفترة (2016-2000).
وقد ربطت مصر عملتها بالدولار الأمريكي عام 1991ثم عدل في منتصف عام 2000 إلى نظام الربط

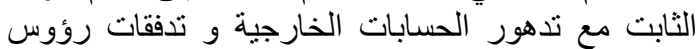

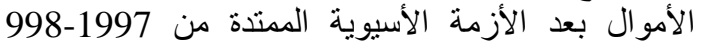

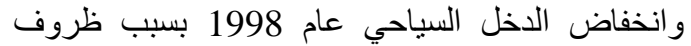
الإرهاب و المغالاة في تقييم الجنيه مقابل الدولار الإن الأمريكي

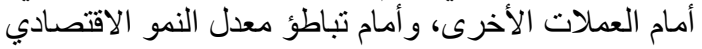

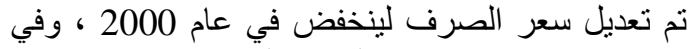

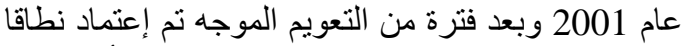

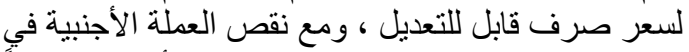

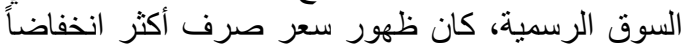
بالسوق الموازية، ومع نهاية عام 2003 تم تعويم سعر الرئر

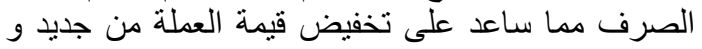

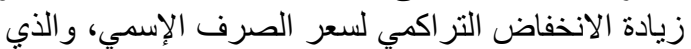

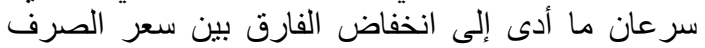

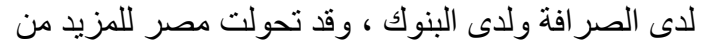

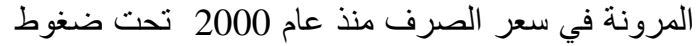

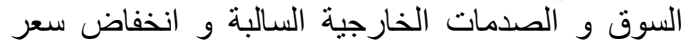

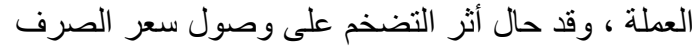

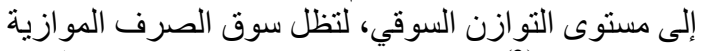
هي الواضحة(2)، وفى نهاية عام 2016 نم تعويم الجنبه مرة أخرى لتنخفض بذللك قيمة الجنيه لتصبح فى السوق السوق الموازية ما بين (20:18) جنيه/دو لار.

مشكلة الار ماسة:

تعاني مصر من عجز في موازين مدفواتواتهاتها بسبب

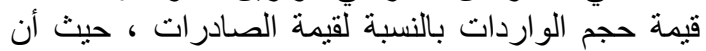

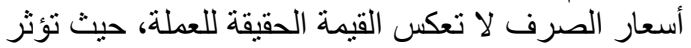

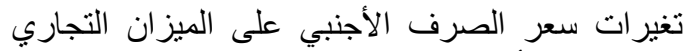

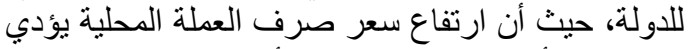

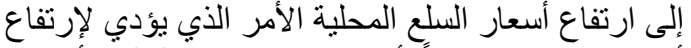

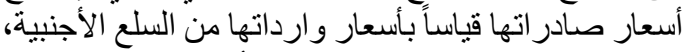

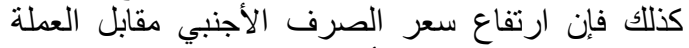

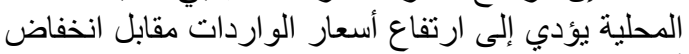

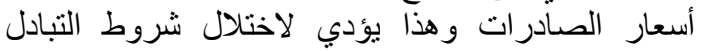

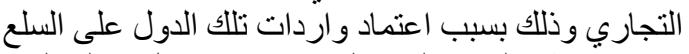

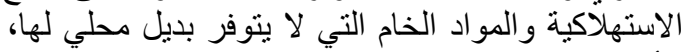

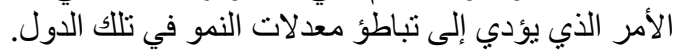
وقد قامت مصر بتخفيض سعر صرف الجنيه المصرى مقابل الدولار، حيث بإنخفاض العملة المصرية التى ليس لها مز ايا تصديرية بعملة الاستير اد (مثل الدول

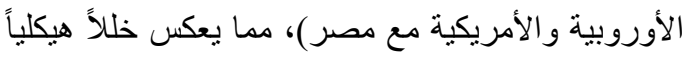

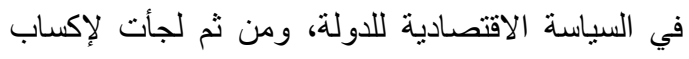

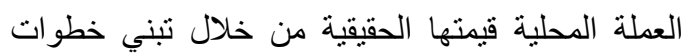
تدريجية لتحرير سعر صرف الجنيه المصري. وقد تبنت 


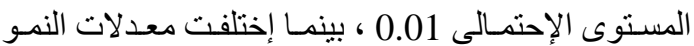

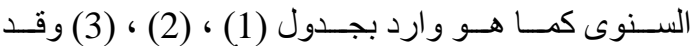

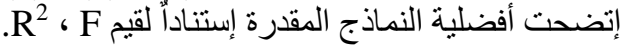

وقد تبين أن سعر الصرف قد بلغ حوالى 5.7 جنيه/دولار خلال متوسط فترة ما قبل الثورة (2004-

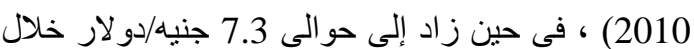

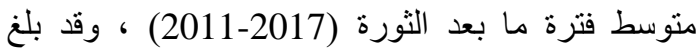
معدل التغير بين فترتى ما قبل وبعد الثورة حوالى بـى 28.1\%، مما يشير إلى التأثثر السلبى للثورة الذى أدى إلى لـى تخفيض قيمة الجنيه المصرى أمام سعر صرف الديل الدولار. كما تبين زيادة سعر صرف الدولار مقابل الجنيه من حوالى 10.187 جنيه/ دولار عام 2016 إلى حوالى 17.904 جنيه/دو لار خلال الربع الأول من عام 2017 مع دع لان بداية تحرير سعر الصرف وتعويم الجنيه المصرى، حيث مثلت الزيادة حو الى 75.8\% من عام 2016. كما تبين إنخفاض إجمالى قيمة الصادرات السلعية الكلية إلى حوالى 18.651 مليار دولار عام 2015 ، الإ أنه مع بداية تحرير سعر الصرف وتعويم الجنيه المصرى تبين زيادة إجمالى قيمة الصادر ات مرة أخرى لتبلغ حو الى لى 20.015 مليار دولار عام 2016 ، بنسبة زيادة بلغت

$$
\text { حوالى 7.3\% من عام 2015- جدول (2). }
$$

كما تبين أن إجمالى قيمة الصـادرات السلعية المصرية

الكلية قد إتخذت إتجاهاً عاماً متز ايداً بلغ حوالى لئ 1.471 مليار دولار يمثل حوالى 8 \% من المتوسط البالغ حوالى 18.28 مليار دولار ، حيث بلغت حولى الى 19.2 مليار

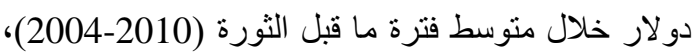
فى حين زادت إلى حوالى 25.6 مليار دولار خلال متوسط فترة ما بعد الثورة (2016-2011)، وقد بلغ معدل التغير بين فترتى ما قبل وبعد الثورة حو الى 33.4 \%؛، مما يشير إلى التأثير الإيجابى للثورة على زيادة إجمالى قيمة

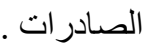

فى حين تبين أن إجمالى قيمة الواردات قد إتخذت إتجاهاً عاماً متز ايداً بلغ حوالى لئ إنى 4.548 مليار دولار يمثل

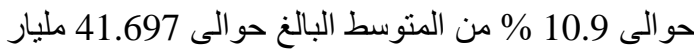
دولار ، حيث إنخفضت مع بداية تحرير سعر الصرف مون

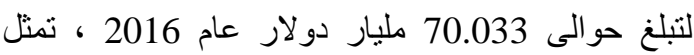
حوالى 9.1 \% من عام 2015. حيث تبين أن إجمالى قيمة
7- وضع نموذج قياسى لقياس أثر تغير سعر الصرف الكرة

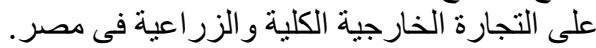

\section{الطريقة البحثية:}

اعتمــدت الدر اســـة علـــى إســـتخدام أدوات التـليـلـل

الإحصـائى و الاقتصـاد القياسـى حيـث تـم إسـتخدام إختبـار

الإرتبـاط بـين المتغيـرات Cross correlation، إختبـار سـبيية جرانجـر Granger Causality وهــو إختبـار إحصائى يستخدم للتأكد من (وجود علاقة سببية تبادلية أى ولى إنى

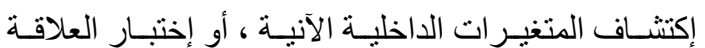
الز ائفـة Spurious أى لا يوجد علاقـة سـبيبة ، أو إختبـار وجـود علاقـة سـببية فـى إتجـاه و احــد )، اختبــار وحـدة الجذور Unit Root Test وهو اختبار إحصـائى يستخدم

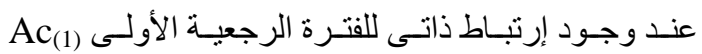

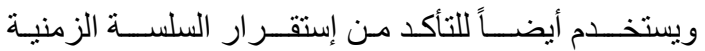
ويستخدم إختبـار ات ) Augmented Dickey -Fuller Schwarz Test Akaike ، Bayesian Criterion (S.B.C) Likelihood و Information Criterion (A.I.C) و Ratio (L.R) التقدير ات فحى عدد من المتغير ات أو المعـالم وخاصـة فى وسى

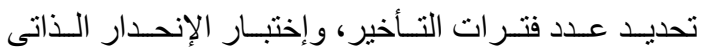
Vector Auto Regression Test (V.A.R) نمـوذج للمعـادلات الغير هيكليـة يستخدم كحل بديل للتنبؤ الديناميكى للمتغير ات الداخلية للبيانات الساكنة فقط. مصادر البيانات:

استندت الدر اسة بصفة أساسية على البيانـات المنشورة

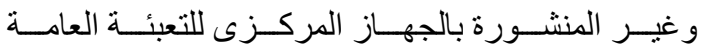

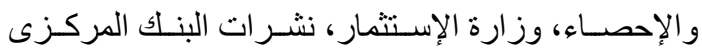

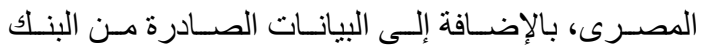
الاحتبـاطي الفيدر الي في سـانت لـويس بالو لايـات المتحدة

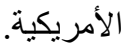

النتائج البحثية والمناقشة المعائة

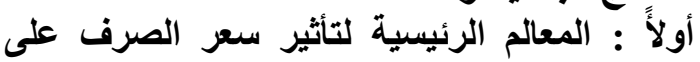

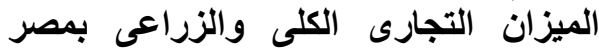

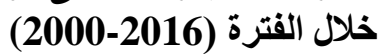

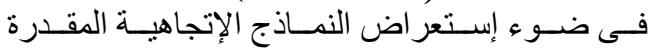

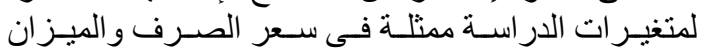

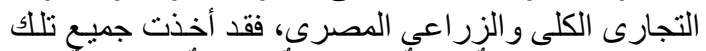

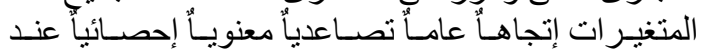


(2010-2004)، في حين زادت إلى حو الى 42.1 مليار

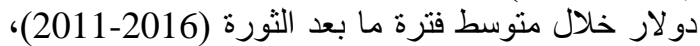

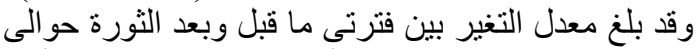

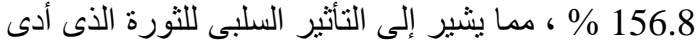

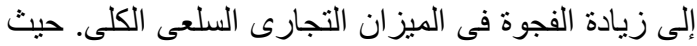

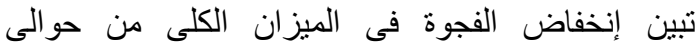
58.393 مليار دولار عام 2015 إلى حوالى لئى 50.018

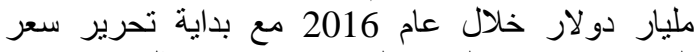
الصرف وتعويم الجنيه المصرى، حيث مثل مثل الإنخفاض بـاض حو الى 14.3\% من عام 2015- جدول (2).

الواردات السلعية المصرية الكلية قد بلغت حوالى 35.6 مليار دولار خلال منوسط فترة ما قبل الثورة (20042010)، فى حين زادت إلى حوالى 67.7 مليار دولار خلال منوسط فترة ما بعد الثورة (2016-2011)، وقد بلغ معدل التغير بين فترنى ما قبل وبعد الثورة حوالى 90.2 \%، مما يشير إلى التأثير السلبى للثورة على زيادة إجمالى لئى قيمة الواردات السلعية المصرية الكلية- جدول (2). كما تبين أن الفجوة فى الميزان التجارى الكلى قد بلغت

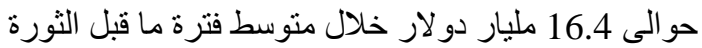
جدول (1): تطور سعر صرف الدولار مقابل الجنيه المصرى خلال الفترة (2000- 2017)

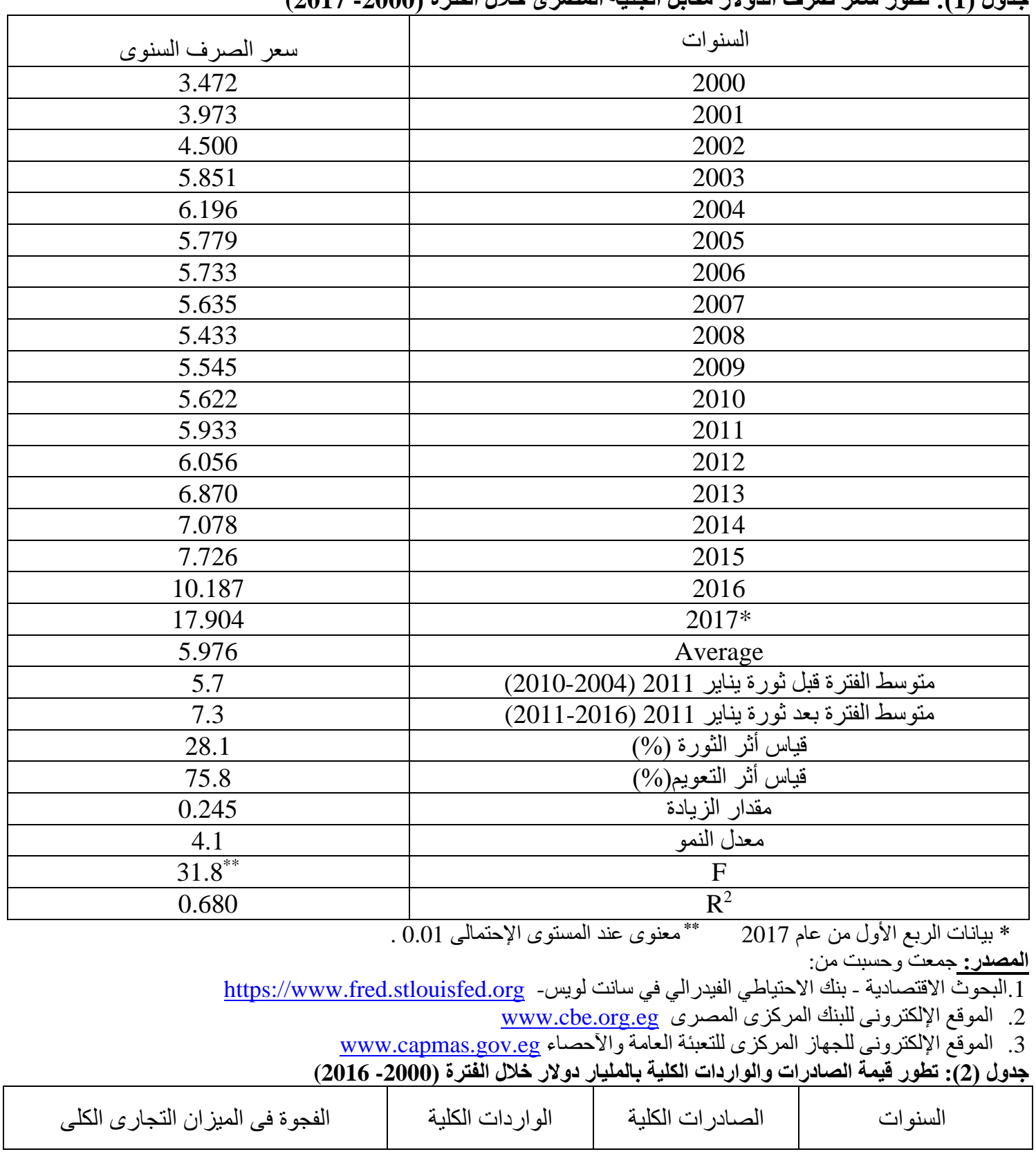


Effect of Exchange Rate Change on Total Foreign and Agricultural Trade

\begin{tabular}{|c|c|c|c|}
\hline-9.302 & 14.578 & 5.276 & 2000 \\
\hline-8.551 & 13.376 & 4.825 & 2001 \\
\hline-7.224 & 12.770 & 5.546 & 2002 \\
\hline-5.542 & 12.950 & 7.408 & 2003 \\
\hline-6.289 & 15.950 & 9.661 & 2004 \\
\hline-9.537 & 22.449 & 12.912 & 2005 \\
\hline-10.572 & 27.300 & 16.728 & 2006 \\
\hline-17.876 & 37.100 & 19.224 & 2007 \\
\hline-22.158 & 48.382 & 26.224 & 2008 \\
\hline-21.884 & 44.946 & 23.062 & 2009 \\
\hline-26.485 & 52.923 & 26.438 & 2010 \\
\hline-28.375 & 58.903 & 30.528 & 2011 \\
\hline-39.791 & 69.200 & 29.409 & 2012 \\
\hline-31.169 & 59.662 & 28.493 & 2013 \\
\hline-44.915 & 71.282 & 26.367 & 2014 \\
\hline-58.393 & 77.044 & 18.651 & 2015 \\
\hline-50.018 & 70.033 & 20.015 & 2016 \\
\hline-23.417 & 41.697 & 18.280 & المتوسط \\
\hline 16.4 & 35.6 & 19.2 & قبل ثورة يناير 2011 \\
\hline 42.1 & 67.7 & 25.6 & بعد ثورة يناير 2011 \\
\hline 156.8 & 90.2 & 33.4 & قياس أثر الثورة \\
\hline-14.3 & -9.1 & 7.3 & قياس أثر التعويم \\
\hline 3.077 & 4.548 & 1.471 & مقدار الزيادة \\
\hline 13.1 & 10.9 & 8.0 & معدل النمو \\
\hline $99.8^{*}$ & $248.6^{*}$ & $29.2^{*}$ & $F$ \\
\hline 0.943 & 0.661 & 0.64 & $\mathrm{R}^{2}$ \\
\hline
\end{tabular}

https://www.fred.stlouisfed.org-1

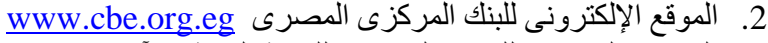
3ww.capmas.gov.eg 3.

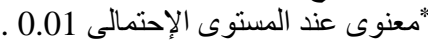

جدول (3): تطور إجمالى قيمة الصادرات والواردات المصرية الزراعية بالمليار دولار خلال الفترة (2000- 2016)

\begin{tabular}{|c|c|c|c|}
\hline الفجوة فى الميز ان الزر اعى & الو اردات الزر اعيه & الصادر ات الزر اعيه & السنوات \\
\hline-3.272 & 3.796 & 0.524 & 2000 \\
\hline-3.091 & 3.646 & 0.555 & 2001 \\
\hline-2.509 & 3.362 & 0.853 & 2002 \\
\hline-1.908 & 2.837 & 0.929 & 2003 \\
\hline-1.621 & 2.854 & 1.233 & 2004 \\
\hline-2.770 & 3.851 & 1.082 & 2005 \\
\hline-3.502 & 4.357 & 0.855 & 2006 \\
\hline-3.813 & 4.788 & 0.975 & 2007 \\
\hline-3.443 & 5.525 & 2.082 & 2008 \\
\hline-2.813 & 5.176 & 2.363 & 2009 \\
\hline-3.295 & 5.522 & 2.227 & 2010 \\
\hline-4.181 & 8.003 & 3.822 & 2011 \\
\hline
\end{tabular}




\begin{tabular}{|c|c|c|c|}
\hline-11.420 & 15.901 & 4.481 & 2012 \\
\hline-9.362 & 14.441 & 5.078 & 2013 \\
\hline-11.069 & 16.256 & 5.187 & 2014 \\
\hline-8.321 & 13.141 & 4.821 & 2015 \\
\hline-6.302 & 11.766 & 5.464 & 2016 \\
\hline-4.864 & 7.366 & 2.502 & المتوسط \\
\hline 3.0 & 4.6 & 1.5 & بل ثورة يناير 2011 \\
\hline 8.4 & 13.3 & 4.8 & مد ثورة يناير 2011 \\
\hline 178.0 & 189.2 & 211.2 & قياس أثر الثورة \\
\hline-24.3 & -10.5 & 13.3 & قياس أثر التعويم \\
\hline 0.469 & 0.816 & 0.347 & مقدار الزيادة \\
\hline 9.6 & 11.1 & 13.9 & معدل النمو \\
\hline $18.4^{*}$ & $38.3^{*}$ & $114.3^{*}$ & $\mathrm{~F}$ \\
\hline 0.551 & 0.719 & 0.834 & $\mathrm{R}^{2}$ \\
\hline
\end{tabular}

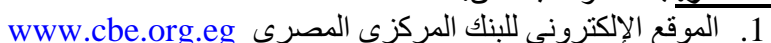
2. * معنوى عند المستوى الإحتمالى المكرى 0.01 .

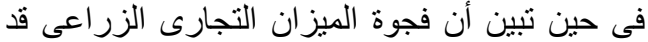

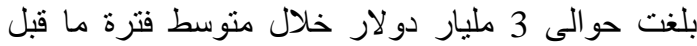

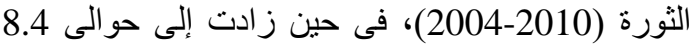

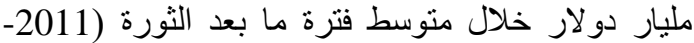

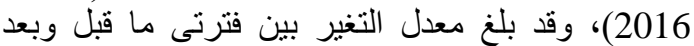

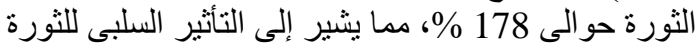

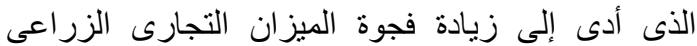

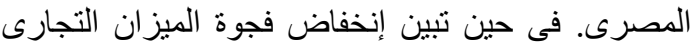

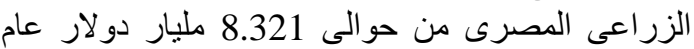

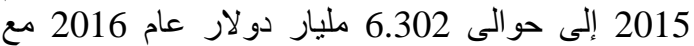
بداية تحرير سعر الصرف وتعويم الجنيه المصرى، حيث

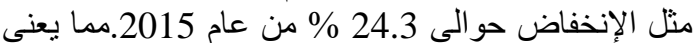
أن سياسة تعويم الجنيه المصرى لها لها أثر إيجابى فى تقليل

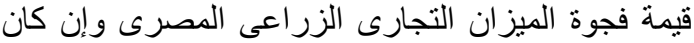

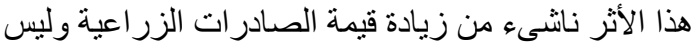
إنخفاض قيمة الو اردات الزر اعية- جدول (3).

ثانيساً: معايير قيساس كفـاءة التجـارة الخارجيـة الكليـة والزراعية المصرية خلال الفترة (2016-2000):

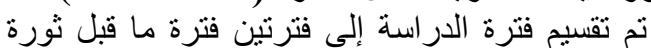

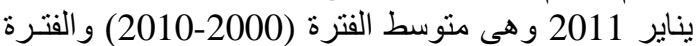
ما بعد ثورة يناير 2011 وهى متوسط الفترة (2011-

2016

وقد تبين من نتائج قياس كفاءة التجارة الخارجية الكلية والزراعية المصرية خلال الفترة (2016-2000)، أن هناك تدهور فى وضع التجارة الخارجية الدصرية وخاصة خلال مرحلة ما قبل ثورة يناير 2011، حيث تبين
في حين تبين أن قيمة الصـادرات الزراعية قد إنخذت

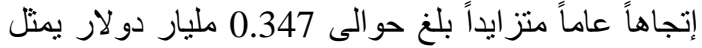

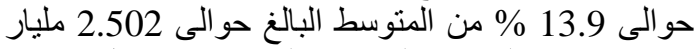

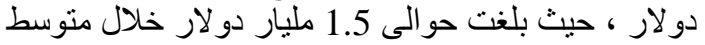

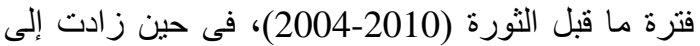

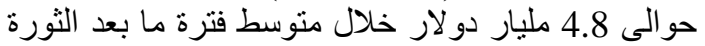

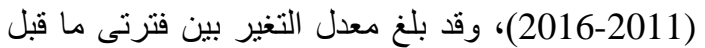

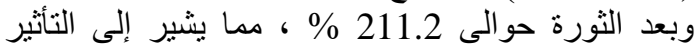

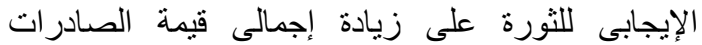
الزراعية. وقد تكون الزيادة فى إجمالى قيمة الصيادة الصادرات

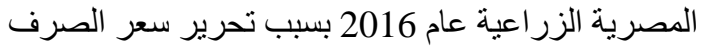
وتعويم الجنيه المصرى ، حيثة حيث منلت حوالى 13.3 \% من

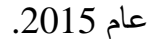

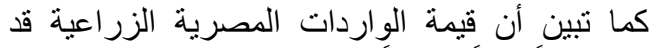
إتخذت إتجاهاً عاماً متز ايداً بلغ حو الى الى 0.816 ملئل اليار دو لار

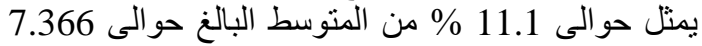
مليار دولار ، حيث بلغت حوالى 4.6 مليار دولار خلال حلال

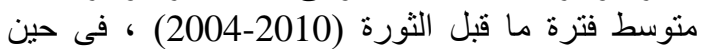

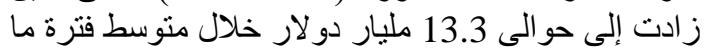
بعد الثورة (2016-2011) ، وقد بلى بلغ معدل التغير بين

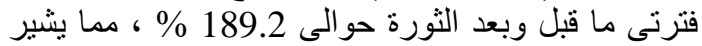

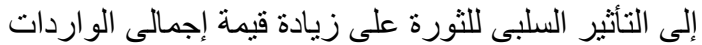

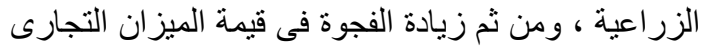

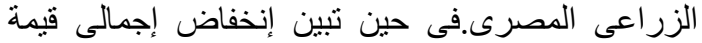

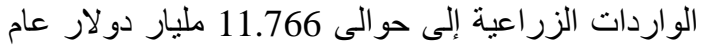
2016 بسبب قرار تحرير سعر الصرف وتلى وتعويم الجنيه

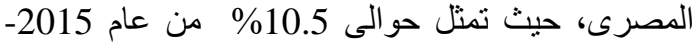
جدول (3). 
الثورة، وحدوث إنخفاض من خلال أثر التعويم- جدول

كما تبين حدوث إنخفاض فى معدل تغطية الصادرات

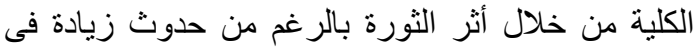

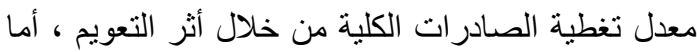
بالنسبة للتجارة الزراعية فقد تبين حدوث زيادة فى معدل

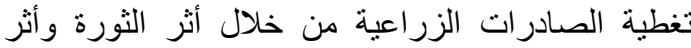

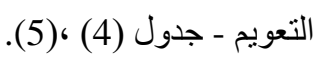

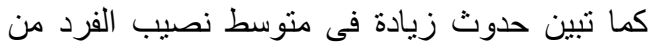

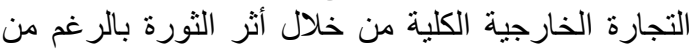

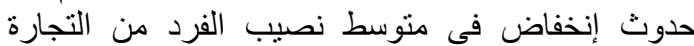

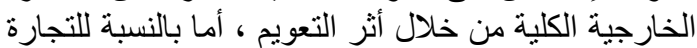

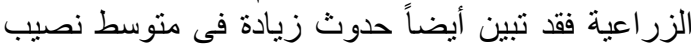

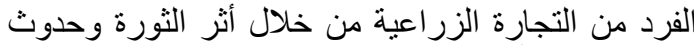

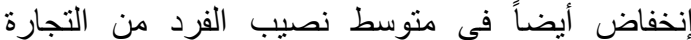

الخارجية الكلية من خلال أثر التعويم - جدول (4) ،(5) التهاب

كما تبين حدوث زيادة فى متوسط نصيب الفرد من

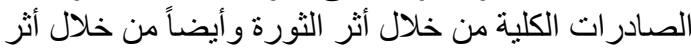

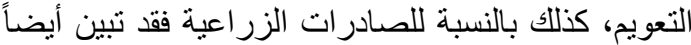
حلوث زيادة في متوسط نصيب الفرد من التراعة الصادرات الزراعية من خلال أثر الثورة وأيضاً من خلال أندادئ التعويم- جدول (4) ، (5). الترن
إنخفاض درجة أهية الصادرات الكلية من خلال أثر الثورة بالرغم من حدوث زيادة فى درجة أهمية الصادر ات التهات الكلية من خلال أثر التعويم، أما بالنسبة للصادرات الزر اعية فق تبين حدوث زيادة فى درجة أهمية الصادرات

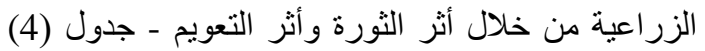
.(5)،

فى حين تبين حدوث إنخفاض فى درجة أهية الواردات الكلية من خلال أثر الثورة وأثر التعويم، أما داثية بالنسبة للواردات الزر اعية فقد تبين حدوث زيادة فى درجة أهية الواردات الزراعية من خلال أثر الثورة، وحدوث إنخفاض من خلال أثر التعويم- جدول (4) ،(5).

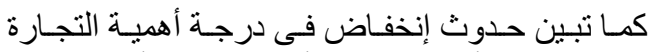

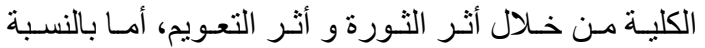

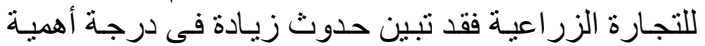

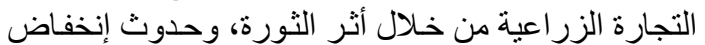

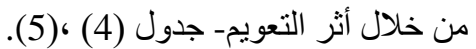

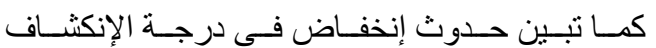

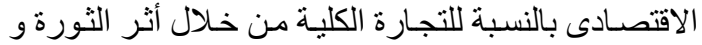

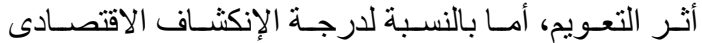

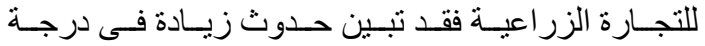
الإنكثـاف الاقتصــادى للتجـارة الزر اعيـة مـن خـلال أثنر

جدول (4) : معايير كفاءة التجارة الخارجية الكلية والزراعية خلال الفترة (2016-2000)

\begin{tabular}{|c|c|c|c|c|c|}
\hline \multirow{2}{*}{\multicolumn{2}{|c|}{ التجارة الخارجية الزر اعية }} & \multirow{2}{*}{\multicolumn{2}{|c|}{ التجارة الخارجية الكلية }} & \multirow[b]{3}{*}{ 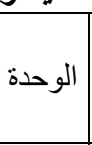 } & \multirow[b]{3}{*}{ 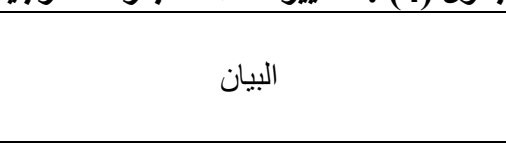 } \\
\hline & & & & & \\
\hline متوسط الفترة & متوسط الفترة & متوسط الفترة & متوسط الفترة & & \\
\hline 1.6 & 1.1 & 8.6 & 13.8 & $\%$ & درجة أهمية الصادر ات \\
\hline 4.4 & 3.4 & 23.0 & 25.1 & $\%$ & درجة أهمية الواردات \\
\hline 6.0 & 4.5 & 31.8 & 38.9 & $\%$ & درجة أهمية التجارة الكلية \\
\hline 6.0 & 4.5 & 31.8 & 38.9 & $\%$ & درجة الإنكشاف الاقتصادى \\
\hline 37.0 & 31.9 & 37.3 & 55.1 & $\%$ & معدل التغطية \\
\hline 212.9 & 83.3 & 1101.9 & 740.4 & 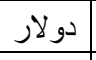 & متوسط نصيب الفرد من التجارة الخارجية \\
\hline 56.6 & 20.9 & 304.4 & 259.7 & 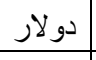 & متوسط نصيب الفرد من الصادر ات دو لار \\
\hline 156.3 & 62.4 & 797.6 & 480.7 & 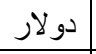 & منوسط نصيب الفرد من الواردات دو لار \\
\hline 3475.1 & 1886.8 & 3475.1 & 1886.8 & 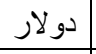 & منوسط نصيب الفرد من إجمالى الناتج المحلى \\
\hline 7.9 & 25.5 & 17.3 & 16.6 & $\%$ & معامل عدم الإستقر ار للصادر ات الكلية \\
\hline 13.4 & 28.5 & 7.0 & 5.9 & $\%$ & معامل عدم الإستقر ارللواردات الكلية \\
\hline 9.6 & 28.0 & 6.7 & 10.3 & $\%$ & معامل عدم الإستقرار للتجارة الكلية \\
\hline 1.5 & 0.5 & 3.3 & 2.6 & $\%$ & معدل النمو للصادر ات الكلية \\
\hline 2.4 & 1.7 & 4.3 & 3.4 & $\%$ & معدل النمو للواردات الكلية \\
\hline
\end{tabular}

جذول (5) : معايير كفاءة التجارة الخارجية الكلية والزراعية خلال الفترة (2016-2000).

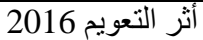

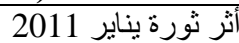
البيان 


\section{E. Mohamed}

\begin{tabular}{|c|c|c|c|c|}
\hline التجارة الزر اعية & التجارة الكلية & التجارة الزر اعية & التجارة الكلية & \\
\hline 9.4 & 3.6 & 49.4 & -38.0 & درجة أهمية الصادر ات \\
\hline-13.6 & -12.3 & 28.8 & -8.4 & درجة أهمية الواردات \\
\hline-7.4 & -9.2 & 33.0 & -18.4 & درجة أهية التجارة الكلية \\
\hline-7.4 & -9.2 & 33.0 & -18.4 & درجة الإنكشاف الاقتصادى \\
\hline 26.6 & 18.1 & 16.0 & -32.3 & معدل التغطية \\
\hline-6.3 & -8.1 & 155.6 & 48.8 & متوسط نصيب الفرد من التجارة الخارجية \\
\hline 10.7 & 4.8 & 170.6 & 17.2 & متوسط نصيب الفرد من الصادر ات دو لار \\
\hline-12.6 & -11.2 & 150.6 & 65.9 & متوسط نصيب الفرد من الو اردات دو لار \\
\hline 1.2 & 1.2 & 84.2 & 84.2 & متوسط نصيب الفرد من إجمالى الناتج المحلى \\
\hline 62.3 & -3.9 & -68.9 & 3.7 & معامل عدم الإستقر ار للصادر ات كلية \\
\hline 3097.1 & 115.6 & -53.0 & 18.4 & معامل عدم الاستقر ار للواردات كلية \\
\hline 3897.4 & 166.3 & -65.7 & -34.7 & معامل عدم الإستقرار للتجارة كلية \\
\hline 9.2 & 3.1 & 228.2 & 26.9 & معدل النمو للصنادرات الكلية \\
\hline 4.3 & 2.9 & 42.5 & 24.8 & معدل النمو للواردات الكلية \\
\hline
\end{tabular}

الزراعية من خلال أثر الثورة ، وحدوث زيادة من خلال أثر التعويم- جدول (4) ،(5).

كما تبين حدوث إنخفاض فى معامل عدم الإستقرار

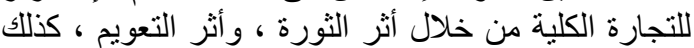

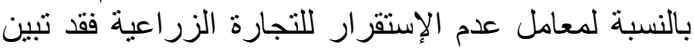

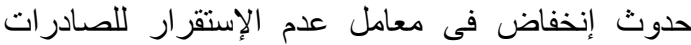

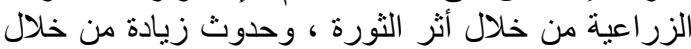

أثر التعويم- جدول (4) ،(5).

كما تبين حدوث زيادة فى معدل نمو الواردات الكلية

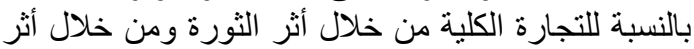

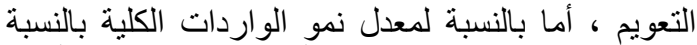

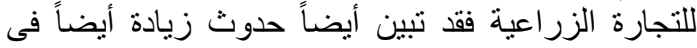

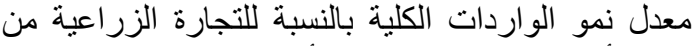

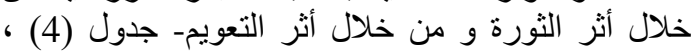

ثالثاً: التقدير القياسى لنموذج أثر تغير سعر الصرف

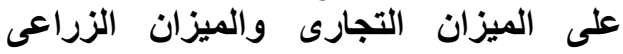
المصرى خلال الفترة (2016-2000)

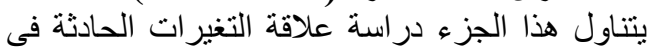

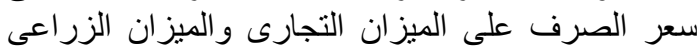

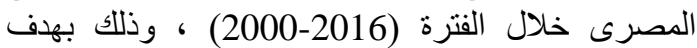

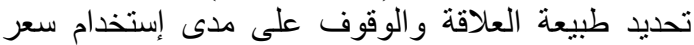

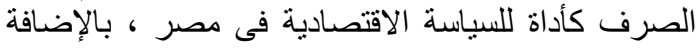

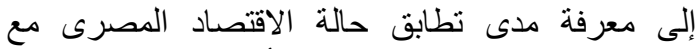

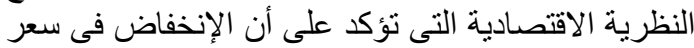

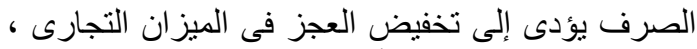

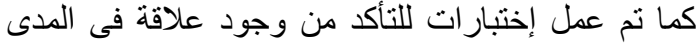

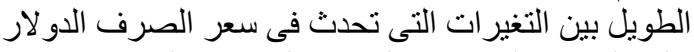

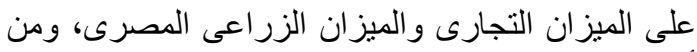

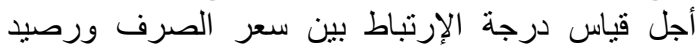

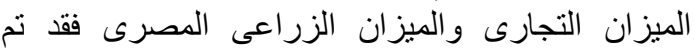

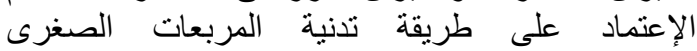

المصدر : جمعت وحسبت من بيانات جداول (3:1) بالدر اسة .

كما تبين زيادة متوسط نصيب الفرد من الواردات

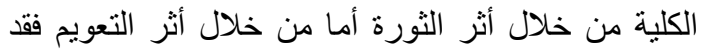

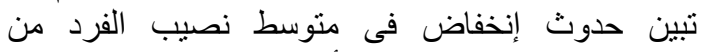

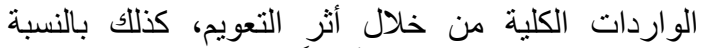

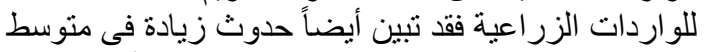

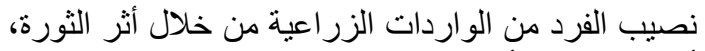

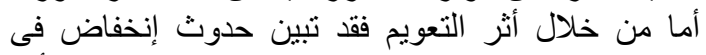

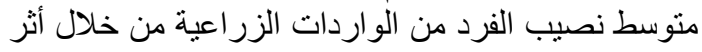

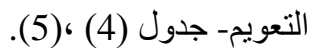

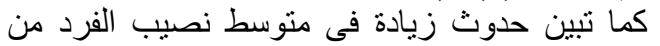

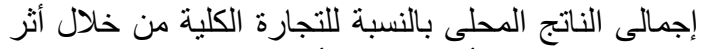

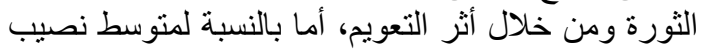

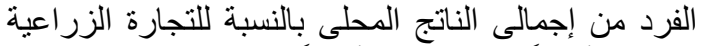

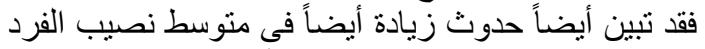

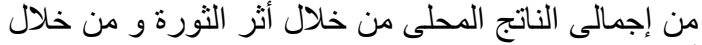

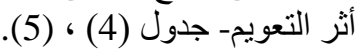

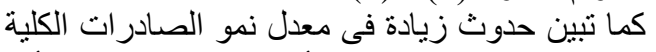

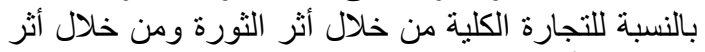

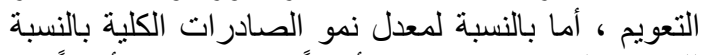

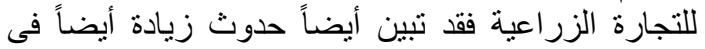

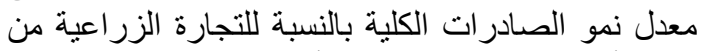
خلال أثر الثورة و من خلال أثر التعويم- جدول (4) ، التهال

كما تبين زيادة معامل عدم الإستقر ار للصادر ات الكلية

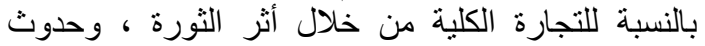

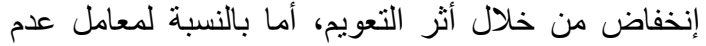

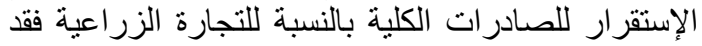

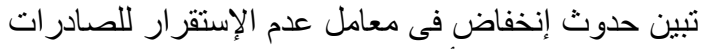

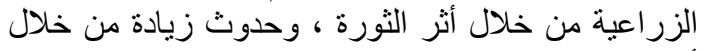

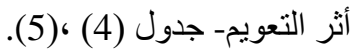

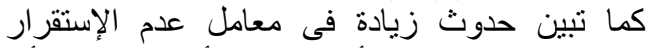

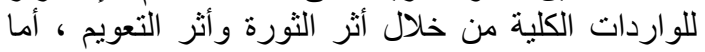
بالنسبة لمعامل عدم الإستقرار للوار إردات الترات الزر اعية فقد تبين

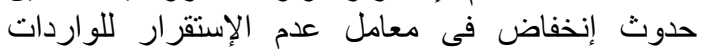


الكلية والواردات الكلية) وسعر صرف الجنيه مقابل

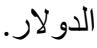

وقد تبين إتفاق هذه النتائج مع النظرية القياسية التى التى التئي تفترض أن أغلب المتغيرات الاقتصادية الكلية غير ساكنة

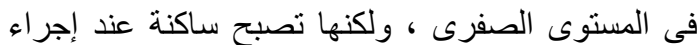

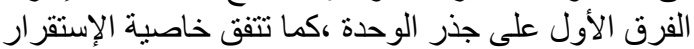

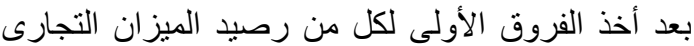

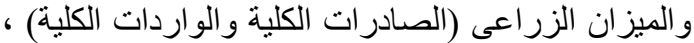

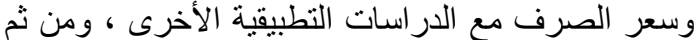

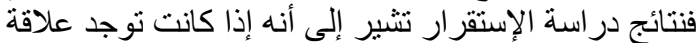

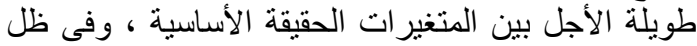

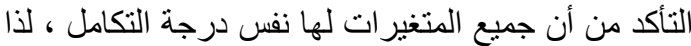

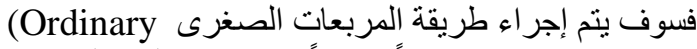

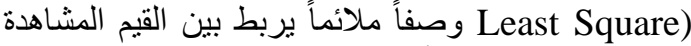

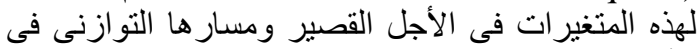

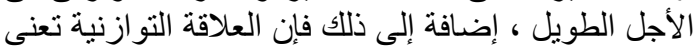

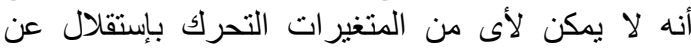

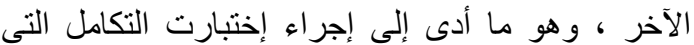
تختبر وجود علاقة توازنية طويلة الأجل بين المتغير التيل التئ الأساسية من عدمه.

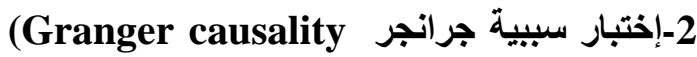
test)

تم إجراء إختبار اتجاه العلاقة السببية بين متغير سعر التبر الصرف و وصبد الميزان التجارى (الصادرات التئية الكلية

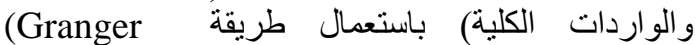

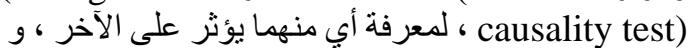

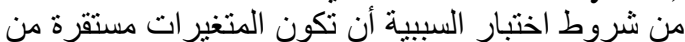
نفس الدرجة و هو شرط تم تحقيقه- جدول (7).

3-التفسير الاحصائي لنتائج نماذج التجارة الخارجية

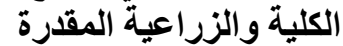

أ_التفسير الاحصائي لنتائج نموذج الصفادة الصادرات الكلية المقدر

تبين من نتائج تقدير نموذج نأثير سعر الصرف على الصى

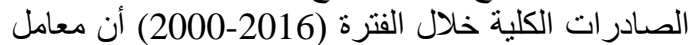

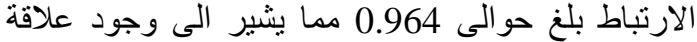
طردية بين المتغير المستقل (الصادرات الكيات الكلية) و المتغير التابع (سعر الصرف) ، كما بلغ معامل التحديد المعدل

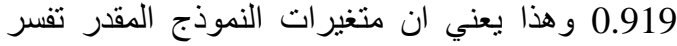

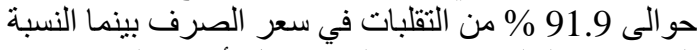
الباقية من التقلبات ترجع الى عوامل في أخرى لم ينضمنها

$\log \left(\hat{\mathrm{Y}}_{1}\right)=4.4363+0.4685 \log \left(\mathrm{X}_{1}\right)+0.8731 \mathrm{AR}_{(1)}$ $\mathrm{R}^{-2}=0.919 \quad \mathrm{~F}=86.1^{*} \quad \mathrm{D} . \mathrm{W}=1.74$ 0.01. معنوية عند مستوى إحتمالى

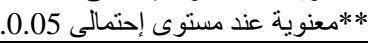

(Ordinary Least Square)

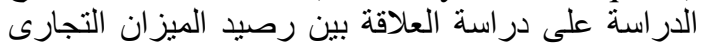

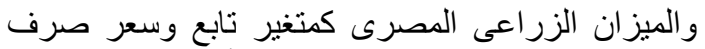

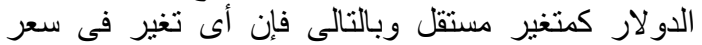

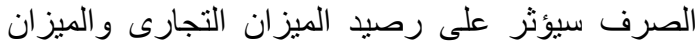

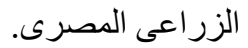

1- إختبار إستقرارية السلاسل الزمنية (Augmented Dickey Fuller test)

تبين من إجراء إختبار Corrologram لجميع متغيرات الدراسة (الميزان التجارى والميزان الزراعى) وسعر الصرف أنها تعانى من مشكلة عدم الإستقرار عند التيز التران

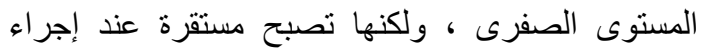

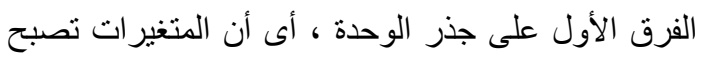

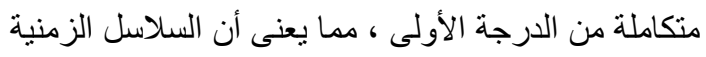

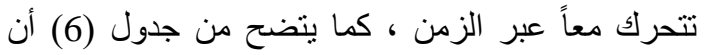
إحتمال وجود جذر الوحدة معدوم ، كما يلاحظ أن القيم

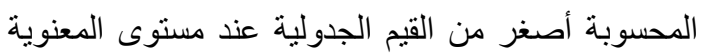

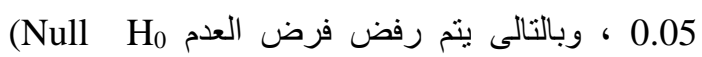
(Alternative وقبول الفرض البديل Hypothesis) Hypothesis) H1 إستقرار كل من سلاسل الميزان التجارى (Difference1)

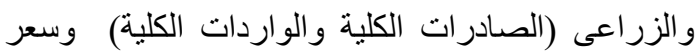
صرف الجنيه مقابل الدو لار ـ شكل (1). ولتقدير العلاقة السببية بين الميزان التجارى

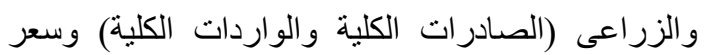

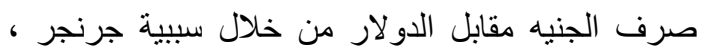
فلابد من توافر شروط إستقرارية السلاسل الزمنية أن تكون من نفس الدرجة ، ولدراسة إستقرارية السلاسل

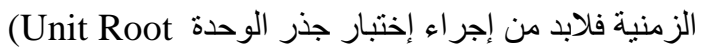

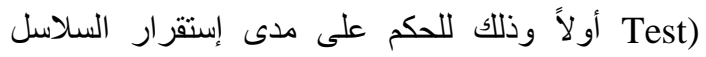
الزمنية لكل المتغيرات خلال فترة الدراسة (20002016) ، وسيتم الإعتماد على إختبار (ديكى فولر الموسع) (Augmented Dickey Fuller test)

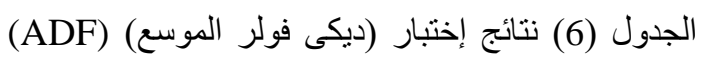
لكل من سلاسل الميزان التجارى والزر اعى (الصادرات

جدول (6) : نتائج إختبار(ADF) للنماذج المقدرة خلال الفترة (2016-2000) 
M. E. Mohamed

\begin{tabular}{|c|c|}
\hline 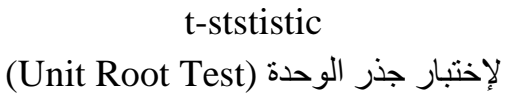 & النموذج \\
\hline$-3.98^{*}$ & سعر الصرف \\
\hline$-3.18^{* *}$ & الصادر ات الكلية \\
\hline$-3.40^{* *}$ & الواردات الكلية \\
\hline$-3.79^{* *}$ & الميزان التجارى الكلى \\
\hline$-3.55^{* *}$ & الصـادرات الزر اعية \\
\hline$-3.50^{* *}$ & الواردات الزراعية \\
\hline$-3.16^{* *}$ & الميزان التجارى الزر اعى \\
\hline
\end{tabular}

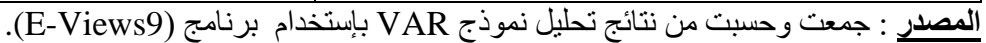

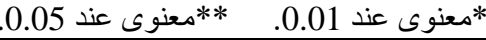

\begin{tabular}{|c|c|c|c|c|c|c|c|c|c|c|c|c|c|c|}
\hline \multicolumn{7}{|c|}{ Correlogram of $\mathrm{D}(\mathrm{Y} 1)$} & \multicolumn{8}{|c|}{ Correlogram of $D(Y 2)$} \\
\hline \multicolumn{7}{|c|}{$\begin{array}{l}\text { Date: 05/29/17 Time: } 19: 30 \\
\text { Sample: } 20002016 \\
\text { Included observations: } 16\end{array}$} & \multicolumn{8}{|c|}{$\begin{array}{l}\text { Date: 05/29/17 Time: } 19: 31 \\
\text { Sample: 2000 } 2016 \\
\text { Included observations: } 16\end{array}$} \\
\hline Autocorrelation & \multicolumn{2}{|c|}{ Partial Correlation } & $A C$ & PAC & Q-Stat & Prob & \multicolumn{2}{|c|}{ Autocorrelation } & \multicolumn{2}{|c|}{ Partial Correlation } & $A C$ & PAC & Q-Stat & Prob \\
\hline $\mathrm{b}$ & $\mathrm{b}$ & 1 & 10.130 & 0.130 & 0.3230 & 0.570 & $1 \square$ & 1 & $1 \square$ & 1 & $1-0.255$ & -0.255 & 1.2529 & 0.263 \\
\hline ] 1 & F & 1 & 20.171 & 0.157 & 0.9269 & 0.629 & 12 & 1 & 10 & 1 & $2-0.080$ & -0.155 & 1.3843 & 0.501 \\
\hline G 1 & $\square$ & 1 & 30.214 & 0.182 & 1.9406 & 0.585 & $1]$ & 1 & & 1 & $\begin{array}{ll}3 & 0.176\end{array}$ & 0.123 & 2.0686 & 0.558 \\
\hline 151 & $1 \square$ & 1 & $4-0.177$. & -0.261 & 2.6936 & 0.610 & & 1 & & 1 & $4 \quad 0.112$ & 0.203 & 2.3712 & 0.668 \\
\hline 1 & 1 & i & $5-0.060$ & -0.087 & 2.7865 & 0.733 & $1 \square$ & 1 & 15 & 1 & $5-0.266$ & -0.173 & 4.2178 & 0.518 \\
\hline 10 & $1 \mathrm{~B}$ & 1 & 60.068 & 0.135 & 2.9213 & 0.819 & 10 & 1 & $1 \square$ & 1 & $6-0.167$ & -0.348 & 5.0166 & 0.542 \\
\hline $1 \square$ & $1 \square$ & 1 & $7-0.385-$ & -0.342 & 7.6694 & 0.363 & $1 \quad \square$ & 1 & & 1 & 70.190 & -0.034 & 6.1701 & 0.520 \\
\hline 10 & 10 & 1 & $8-0.102$. & -0.087 & 8.0461 & 0.429 & 10 & 1 & 1 & 1 & $8-0.147$ & -0.044 & 6.9479 & 0.542 \\
\hline $1 \square$ & 1 & 1 & $9-0.218$. & -0.165 & 10.007 & 0.350 & 10 & 1 & & 1 & $9-0.136$ & -0.040 & 7.7089 & 0.564 \\
\hline 1 & 10 & । & $10-0.157$ & 0.108 & 11.187 & 0.343 & 17 & 1 & 1 & । & $10-0.013$ & -0.155 & 7.7168 & 0.656 \\
\hline 10 & 10 & 1 & $11-0.056$ & -0.120 & 11.367 & 0.413 & 1 & 1 & $1 \square$ & 1 & $11-0.061$ & -0.320 & 7.9306 & 0.720 \\
\hline ] & 11 & 1 & $12-0.024$ & -0.026 & 11.409 & 0.494 & 1 & 1 & 1 & & 120.039 & -0.047 & 8.0413 & 0.782 \\
\hline \multicolumn{7}{|c|}{ نموذج الصادرات الكلية } & \multicolumn{8}{|c|}{ نموذج الواردات الكلية } \\
\hline \multicolumn{7}{|c|}{ Correlogram of $\mathrm{D}(\mathrm{Y} 3)$} & \multicolumn{8}{|c|}{ Correlogram of $\mathrm{D}(\mathrm{Y} 4)$} \\
\hline \multicolumn{7}{|c|}{$\begin{array}{l}\text { Date: 05/29/17 Time: } 19: 32 \\
\text { Sample: } 20002016 \\
\text { Included observations: } 16\end{array}$} & \multicolumn{8}{|c|}{$\begin{array}{l}\text { Date: 05/29/17 Time: } 19: 33 \\
\text { Sample: } 20002016 \\
\text { Included observations: } 16\end{array}$} \\
\hline Autocorrelation & \multicolumn{2}{|c|}{ Partial Correlation } & $A C$ & PAC & Q-Stat & Prob & \multicolumn{2}{|c|}{ Autocorrelation } & \multicolumn{2}{|c|}{ Partial Correlation } & $A C$ & PAC & Q-Stat & Prob \\
\hline 1 & 10 & 1 & $1-0.075$ & -0.075 & 0.1071 & 0.743 & 1 & 1 & 1 & 1 & 10.007 & 0.007 & 0.0009 & 0.976 \\
\hline b 1 & b & 1 & 20.069 & 0.064 & 0.2052 & 0.903 & 10 & 1 & 10 & 1 & $2-0.168$ & -0.168 & 0.5844 & 0.747 \\
\hline 51 & 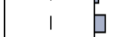 & 1 & $\begin{array}{ll}3 & 0.125\end{array}$ & 0.136 & 0.5504 & 0.908 & 10 & 1 & 10 & 1 & $\begin{array}{ll}30.090 \\
\end{array}$ & 0.095 & 0.7623 & 0.858 \\
\hline 10 & 16 & 1 & $\begin{array}{ll}40.143 \\
4\end{array}$ & 0.163 & 1.0430 & 0.903 & & 1 & $1 \square$ & 1 & $4-0.053$ & -0.087 & 0.8286 & 0.935 \\
\hline $1 \square$ । & $1 \square$ & 1 & $5-0.375$ & -0.387 & 4.7226 & 0.451 & & 1 & & 1 & $\begin{array}{ll}50.096 \\
\end{array}$ & 0.137 & 1.0687 & 0.957 \\
\hline 12 & $1 \square$ & 1 & $6-0.073$ & -0.203 & 4.8754 & 0.560 & 15 & 1 & $1 \square$ & I & $6-0.270$ & -0.332 & 3.1640 & 0.788 \\
\hline 1 & 1 & 1 & $7-0.024$ & -0.019 & 4.8944 & 0.673 & 18 & 1 & 10 & 1 & $7-0.239$ & -0.171 & 4.9966 & 0.660 \\
\hline 10 & 1 पे & 1 & $8-0.225$ & -0.129 & 6.7239 & 0.567 & 17 & 1 & 10 & 1 & $\begin{array}{ll}80.020\end{array}$ & -0.134 & 5.0113 & 0.756 \\
\hline 10 & 1 & 1 & $9-0.174$ & -0.072 & 7.9673 & 0.537 & p & 1 & 17 & 1 & $\begin{array}{ll}9 & 0.105\end{array}$ & 0.140 & 5.4657 & 0.792 \\
\hline 1 & $1 \square$ & 1 & $10-0.095$ & -0.237 & 8.3992 & 0.590 & ๘ & 1 & 15 & 1 & $10-0.075$ & -0.148 & 5.7328 & 0.837 \\
\hline ] & 10 & 1 & $11-0.038$ & -0.123 & 8.4813 & 0.670 & 1 & 1 & $1]$ & 1 & $11-0.051$ & 0.053 & 5.8855 & 0.881 \\
\hline $1 \mathrm{~b}$ & $1 口$ & 1 & $12 \quad 0.076$ & 0.195 & 8.8961 & 0.712 & 1 & 1 & 1 다 & 1 & 120.020 & -0.149 & 5.9130 & 0.920 \\
\hline & جاري الكلا & ك الت الت & ج الميز ار & & & & & & لز لزر اعياً & & t1 & & & \\
\hline
\end{tabular}


Effect of Exchange Rate Change on Total Foreign and Agricultural Trade

\begin{tabular}{|c|c|c|c|c|c|c|c|c|c|c|c|c|c|c|}
\hline \multicolumn{8}{|c|}{ Correlogram of $\mathrm{D}(\mathrm{Y} 5)$} & \multicolumn{7}{|c|}{ Correlogram of $\mathrm{D}(\mathrm{Y} 6)$} \\
\hline \multicolumn{8}{|c|}{$\begin{array}{l}\text { Date: 05/29/17 Time: } 19: 34 \\
\text { Sample: } 20002016 \\
\text { Included observations: } 16\end{array}$} & \multicolumn{7}{|c|}{$\begin{array}{l}\text { Date: 05/29/17 Time: } 19: 35 \\
\text { Sample: } 20002016 \\
\text { Included observations: } 16\end{array}$} \\
\hline \multicolumn{2}{|c|}{ Autocorrelation } & \multicolumn{2}{|c|}{ Partial Correlation } & \multirow{2}{*}{$\frac{A C}{10.009}$} & \multirow{2}{*}{$\frac{P A C}{0.009}$} & \multirow{2}{*}{$\frac{\text { Q-Stat }}{0.0017}$} & \multirow{2}{*}{$\frac{\text { Prob }}{0.967}$} & Autocorrelation & \multicolumn{2}{|c|}{ Partial Correlation } & $\mathrm{AC}$ & PAC & \multirow{2}{*}{$\frac{\text { Q-Stat }}{0.2765}$} & \multirow{2}{*}{ Prob } \\
\hline 1 & I & 1 & 1 & & & & & 1 & 1 & 1 & 10.120 & 0.120 & & \\
\hline 17 & 1 & 7 & । & 20.097 & 0.097 & 0.1959 & 0.907 & 1 & 1 & 1 & 20.019 & 0.005 & 0.2842 & 0.868 \\
\hline $1 \square$ & 1 & $1 \square$ & । & $3-0.307$ & -0.312 & 2.2906 & 0.514 & $1 \square$ & $1 \square$ & 1 & $3-0.272$ & -0.279 & 1.9195 & 0.589 \\
\hline $1 \square$ & 1 & $1 \square$ & 1 & $4-0.223$ & -0.243 & 3.4789 & 0.481 & 15 & 14 & 1 & $4-0.172$ & -0.117 & 2.6315 & 0.621 \\
\hline 1 & 1 & 1 & 1 & $5-0.061$ & 0.001 & 3.5748 & 0.612 & 15 & 1 & 1 & $5-0.090$ & -0.049 & 2.8416 & 0.724 \\
\hline 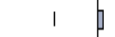 & 1 & । & 1 & 60.067 & 0.027 & 3.7039 & 0.717 & 1 & 1 & 1 & 60.030 & -0.023 & 2.8681 & 0.825 \\
\hline । & 1 & 1 & 1 & 70.048 & -0.100 & 3.7769 & 0.805 & 1 & 19 & 1 & $7-0.033$ & -0.118 & 2.9020 & 0.894 \\
\hline 4 & 1 & 1 당 & 1 & $8-0.072$ & -0.189 & 3.9654 & 0.860 & 15 & 14 & 1 & $8-0.076$ & -0.138 & 3.1116 & 0.927 \\
\hline L & 1 & 10 & 1 & $9-0.087$ & -0.099 & 4.2771 & 0.892 & 1 & 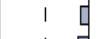 & 1 & $9-0.081$ & -0.093 & 3.3847 & 0.947 \\
\hline 4 & 1 & 1 & 1 & $10-0.089$ & -0.074 & 4.6601 & 0.913 & 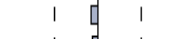 & 15 & 1 & $10-0.069$ & -0.115 & 3.6123 & 0.963 \\
\hline 1 & 1 & 10 & 1 & $11-0.045$ & -0.147 & 4.7780 & 0.941 & q & 14 & 1 & $11-0.052$ & -0.146 & 3.7655 & 0.976 \\
\hline b & 1 & 14 & 1 & 120.057 & -0.086 & 5.0157 & 0.957 & p & 11 & 1 & 120.067 & -0.030 & 4.0879 & 0.982 \\
\hline
\end{tabular}

شكل (1) : الإرتباطات الرجعية والإرتباطات الجزئية لنماذج التجارة الخارجية

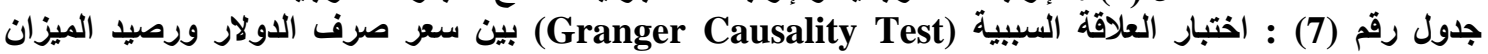
التجاري والزراعى (الصادرات والواردات (اتلات)

\begin{tabular}{|c|c|c|}
\hline Null Hypothesis & F-Statistic & Prob. \\
\hline $\mathrm{D}\left(\mathrm{Y}_{1}\right)$ does not Granger Cause $\mathrm{D}(\mathrm{X})$ & 6.770 & 0.016 \\
\hline $\mathrm{D}(\mathrm{X})$ does not Granger Cause $\mathrm{D}\left(\mathrm{Y}_{1}\right)$ & 0.052 & 0.950 \\
\hline $\mathrm{D}\left(\mathrm{Y}_{2}\right)$ does not Granger Cause $\mathrm{D}(\mathrm{X})$ & 0.814 & 0.473 \\
\hline $\mathrm{D}(\mathrm{X})$ does not Granger Cause $\mathrm{D}\left(\mathrm{Y}_{2}\right)$ & 1.587 & 0.257 \\
\hline $\mathrm{D}\left(\mathrm{Y}_{3}\right)$ does not Granger Cause $\mathrm{D}(\mathrm{X})$ & 0.171 & 0.846 \\
\hline $\mathrm{D}(\mathrm{X})$ does not Granger Cause $\mathrm{D}\left(\mathrm{Y}_{3}\right)$ & 0.435 & 0.660 \\
\hline $\mathrm{D}\left(\mathrm{Y}_{4}\right)$ does not Granger Cause $\mathrm{D}(\mathrm{X})$ & 0.421 & 0.668 \\
\hline $\mathrm{D}(\mathrm{X})$ does not Granger Cause $\mathrm{D}\left(\mathrm{Y}_{4}\right)$ & 0.659 & 0.541 \\
\hline $\mathrm{D}\left(\mathrm{Y}_{5}\right)$ does not Granger Cause $\mathrm{D}(\mathrm{X})$ & 0.024 & 0.976 \\
\hline $\mathrm{D}(\mathrm{X})$ does not Granger Cause $\mathrm{D}\left(\mathrm{Y}_{5}\right)$ & 0.228 & 0.800 \\
\hline $\mathrm{D}\left(\mathrm{Y}_{6}\right)$ does not Granger Cause $\mathrm{D}(\mathrm{X})$ & 0.053 & 0.949 \\
\hline $\mathrm{D}(\mathrm{X})$ does not Granger Cause $\mathrm{D}\left(\mathrm{Y}_{6}\right)$ & 0.586 & 0.577 \\
\hline
\end{tabular}

المصدر : جمعت وحسبت بإستخدام برنامج (E-Views9) من بيانات جداول (3:1).

يترتب عن ذللك تنازل الأجانب على قدر من عملاتهم

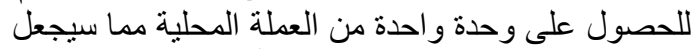

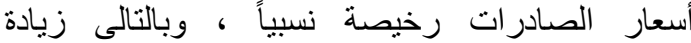

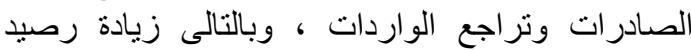

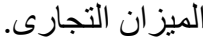

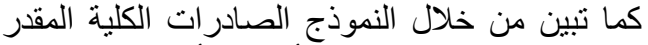

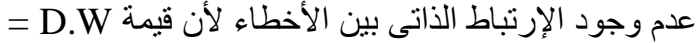

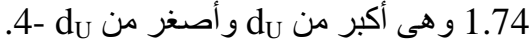

ويشير معدل التغير لسعر الصرف أنه إذا إرتفع سعر

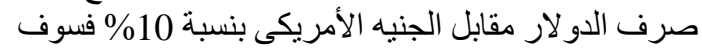

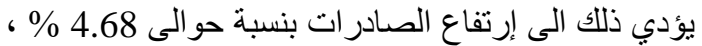

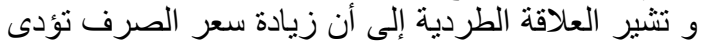

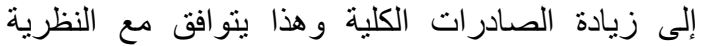
الاقتصادية ، وتفسير ذلك أنه عند إرتفاع سعر الصرف الكرف

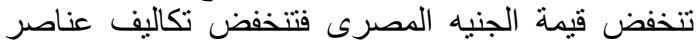

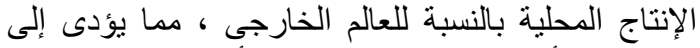
إنخفاض الأسعار المحلية مقارنة بالأسعار العالمبة ، و و العالئ 


\section{E. Mohamed}

$$
\begin{aligned}
& \mathrm{R}^{-2}=0.97 \quad \mathrm{~F}=243.9^{*} \quad \mathrm{D} . \mathrm{W}=1.68 \\
& \text { * معنوية عند مستوى إحتمالى } 0.01 .
\end{aligned}
$$

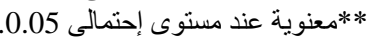

ويشير معدل التغير لسعر الصرف أنه إذا إرتفع سعر

صرف الجنيه مقابل الدو لار الأمريكى بنسبة 10\% فسوف يؤدي ذلك الى إرتفاع رصيد الميزان التجارى بنسبة حوالى 9.1 \% ، حيث تتير العلاقة الطردية إلى أن زيادة سعر الصرف يؤدى إلى زيادة رصيد الميزان التجارى و هذا يتو افق مع النظرية الاقتصادية ، وتفسير ذلك أنه عند إرتفاع سعر الصرف تتخفض قيمة الجنيه المصرى يؤدى إلى إنخفاض تكاليف عناصر الإتتاج المحلية بالنسبة للعالم الخارجى ، مما يؤدى إلى إنخفاض الأسعار الدحلية مقارنة

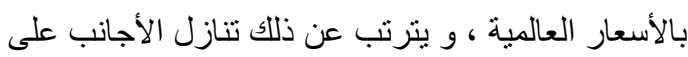
قدر من عملاتهم للحصول على وحدة واحدة من العملة المحلية مما سيجعل أسعار رصيد الميزان التجارى رخيصة نسبياً ، مما يؤدى إلى زيادة الصدرات وتراجع الواردات ، وبالتالى زيادة رصيد الميزان التجارى. وتبين من نموذج رصيد الميزان التجارى عدم وجود الإرتباط الذاتى بين الأخطاء لأن قيمة D.W = 1.68 وهى أكبر

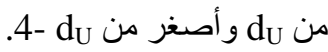

\section{دـالتفسير الاحصائي لنتائج نموذج الصادرات الزراعية المقدر}

تبين من نتائج تقدير نموذج تأثير سعر الصرف على

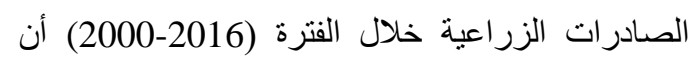
معامل الارتباط بلغ حوالى 0.950 مما يشير الى وجود علاقة طردية بين المتغير المستقل (الصادرات الزراعية) و المتغير التابع (سعر الصرف) ، كما بلغ معامل التحديد المعدل 0.888 و هذا يعني ان متغيرات النموذج المقدر تفسر حوالى 88.8\% من التقلبات في سعر الصرف بينما النسبة الباقية من التقلبات ترجع الى عوامل أخرى لم لمالى

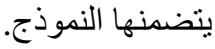

$\log \left(\hat{\mathrm{Y}}_{4}\right)=2.403+0.064 \log \left(\mathrm{X}_{1}\right)+0.928 \mathrm{AR}_{(1)}$ $(0.69) \mathrm{n}$ (1.98) (10.59) *
ب_التفسير الاحصائي لنتائج نموذج الواردات الكلية المقدر

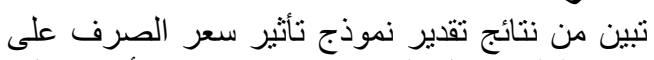

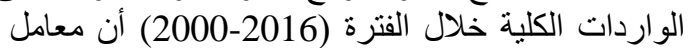

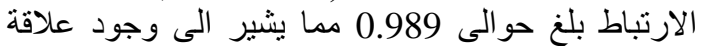
عكسية بين المتغير المستقل (الواردات الكئل الكلية) والمتغير

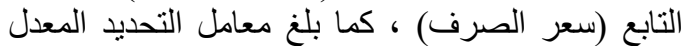

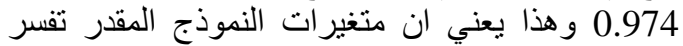
حو الى 97.4 \% من التقلبات في سعر الصرف بئ بينما النسبة الباقية من التقلبات نرجع الى عوامل في أخرى لم ينضمنها

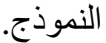

$$
\begin{aligned}
& \log \left(\hat{\mathrm{Y}}_{2}\right) \underset{(0.91) \mathrm{n}}{15.003}-\underset{(4.1-)^{*}}{1.171} \log \left(\mathrm{X}_{1}\right)+0.9814 \mathrm{AR}_{(1)} \\
& \mathrm{R}^{-2}=0.974 \quad \mathrm{~F}=282.8^{*} \quad \text { D.W }=1.83 \\
& \text { *منوية عند مستوى إحتمالى } 0.01 .
\end{aligned}
$$

ويثير معدل التغير لسعر الصرف أنها إذا إرتفع سعر

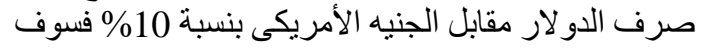

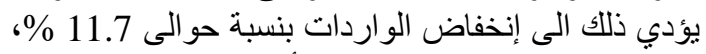

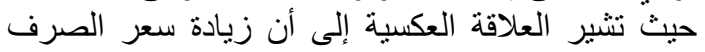

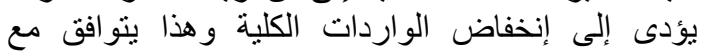

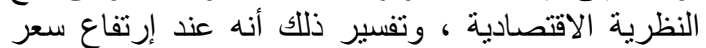

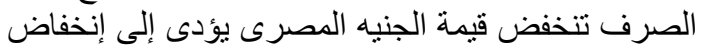

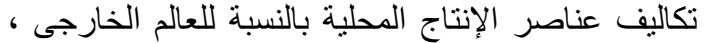

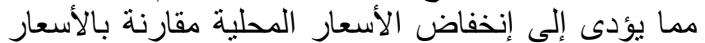

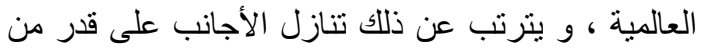

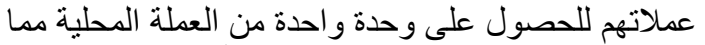

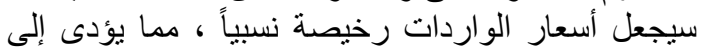

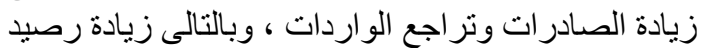

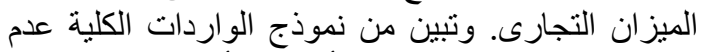

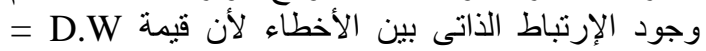

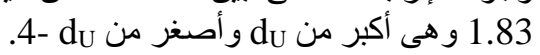

\section{ج-التفسير الاحصائي لنتائج نموذج رصيد الميزان التجارى المقدر}

تبين من نتائج تقدير نموذج نأثير سعر الصرف على الصفا

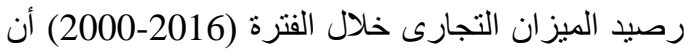
معامل الارتباط بلغ حوالى 0.987 مما يشبر الى وجود علاقة طردية بين المتغير المستقل (رصيد الميزان التجارى) و المتغير التابع سعر الصرف) ، كما بلغ معامل التحديد 0.970 و هذا بعني ان متغير ات النموذج المقدر تفسر حوالى 97 \% من التقلبات في سعر الصرف بين بندات

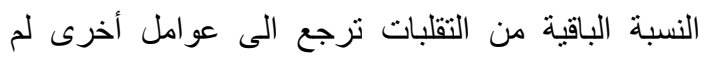
يتضمنها النموذج. $\log \left(\hat{\mathrm{Y}}_{3}\right)=8.609+0.911 \log \left(\mathrm{X}_{1}\right)+0.951 \mathrm{AR}_{(1)}$ 
n :non significant . معنوية عند مستوى إحتمالى 0.05*

ويشير معدل التغير لسعر الصرف أنه إذا إرتفع سعر

صرف الجنيه مقابل الدولار الأمريكى بنسبة 10\% فسوف يؤدي ذلك الى إنخفاض الواردات بنسبة حو الى 13 \% ، و تشير العلاقة العكسية إلى أن زيادة سعر الصرف يؤدى إلى إنخفاض الواردات الزراعية و هذا يتوافق مع النظرية الاقتصادية ، وتفسير ذلك أنه عند إرتفاع سعر الصرف تنخفض قيمة الجنيه المصرى يؤدى إلى إنخفاض تكاليف عناصر الإنتاج المحلية بالنسبة للعالم الخارجى ، مما يؤدى إلى إنخفاض الأسعار المحلية مقارنة بالأسعار العالمية ، و يترتب عن ذلك تنازل الأجانب على قدر من عملاتهم للحصول على وحدة و احدة من العملة المحلية مما سبجعل أسعار الواردات رخيصة نسبياً ، مما بؤدى إلى زيادة الصادرات وتراجع الواردات ، وبالتالى زيادة رصيد الميزان الزراعى. وتبين من نموذج الواردات الزراعية = D.W عدم وجود الإرتباط الذاتى بين الأخطاء لأن قيمة 1.64 وهى أكبر من du و أصغر من du d-

و-التفسير الاحصائي لنتائج نموذج رصيد الميزان الزراعى المقار

تبين من نتائج تقدير نموذج نأثير سعر الصرف على الصى

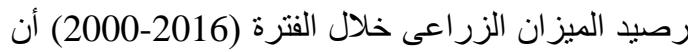

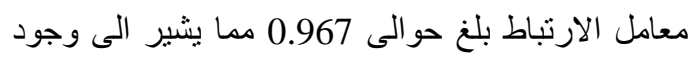
علاقة طردية بين المتغير المستقل (رصيد الميزان الزراعى) و المتغير التابع سعر الصرف) ، كما بلغ معامل (لين التحديد المعدل 0.926 وهذا يعني ان منغيرات النموذج المقدر تفسر حوالى 92.6 \% من التقلبات في سعر الصرف بينما النسبة الباقية من التقلبات ترجع الى عوامل أخرى لم يتضمنها النموذج.

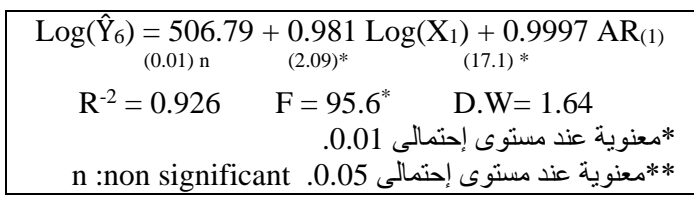

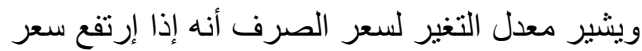

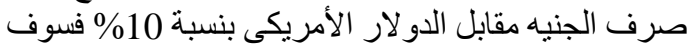

$$
\begin{array}{r}
\mathrm{R}^{-2}=0.888 \quad \mathrm{~F}=60.4^{*} \quad \mathrm{D} . \mathrm{W}=2.03 \\
.0 .01 \text { معنوية عند مستوى إحتمالى * معنوية عند مستوى إحتمالى * * م } 05 \\
\text { n :non significant }
\end{array}
$$

ويشير معدل التغير لسعر الصرف أنه إذا إرتفع سعر صرف الجنيه مقابل الدولار الأمريكى بنسبة 10\% فسوف يؤدي ذلك الى إرتفاع الصادر ات بنسبة حو الى 0.64 \% ، حيث تشير العلاقة الطردية إلى أن زيادة سعر الصرف يؤدى إلى زيادة الصادرات الزراعية وهذا يتوافق مع النظرية الاقتصادية ، وتفسير ذلك أنه عند إرتفاع سعر الصرف تتخفض قيمة الجنيه المصرى يؤدى إلى إنخفاض تكاليف عناصر الإنتاج المحلية بالنسبة للعالم الخارجى ، مما يؤدى إلى إنخفاض الأسعار المحلية مقارنة بالأسعار العالمية ، و ينرتب عن ذللك تنازل الأجانب على قدر من عملاتهم للحصول على وحدة واحدة من العملة المحلية مما سيجعل أسعار الصادرات رخيصة نسبياً ، مما يؤدى إلى زيادة الصادرات وتر اجع الواردات ، وبالتالى زيادة رصيد الميزان الزراعى. وتبين من نموذج الصادرات الزراعية = D.W عدم وجود الإرتباط الذاتى بين الأخطاء لأن قيمة 2.03 و هى أكبر من du و أصغر من dU -4 -4.

\section{هـالتفسير الاحصائي لنتائج نموذج الواردات} الزراعية المقدر

تبين من نتائج تقدير نموذج تأثير سعر الصرف على الواردات الزر اعية خلال الفترة (2016-2000) أن معامل الارتباط بلغ حوالى 0.953 مما يثير الى وجود علاقة عكسية بين المتغير المستقل (الواردات الزر اعية) و المتغير التابع (سعر الصرف) ، كما بلغ معامل التحديد المعدل 0.894 وهذا يعني ان منغيرات النموذج المقدر تفسر حو الى 89.4 \% من التقلبات في سعر الصرف بينما النسبة الباقية من التقلبات ترجع الى عوامل أخرى لم يتضمنها النموذج.

$\log \left(\hat{\mathrm{Y}}_{5}\right)=375.081-1.302 \log \left(\mathrm{X}_{1}\right)+0.999 \mathrm{AR}_{(1)}$ $\begin{array}{lll}(0.01) \mathrm{n} & (2.40-) * * \quad(15.09) *\end{array}$

$$
\mathrm{R}^{-2}=0.894 \quad \mathrm{~F}=64.2^{*} \quad \mathrm{D} \cdot \mathrm{W}=1.64
$$

* معنوية عند مستوى إحتمالى 0.01. 
فولر الموسع) (ADF) حيث يتبين من خلال جدول رقم

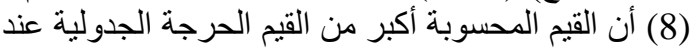

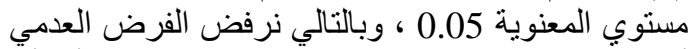

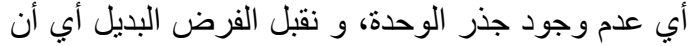

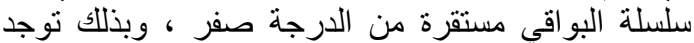

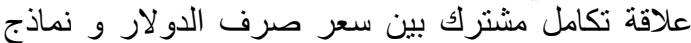
التجارة الخارجية الكلية و الزر اعية.

\section{5-إختبار التوزيع الطبيعى لبواقى نماذج التجارة} الخارجية الكلية والزراعية الطبية

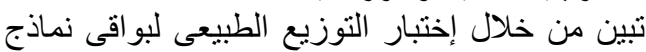

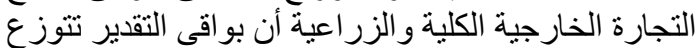

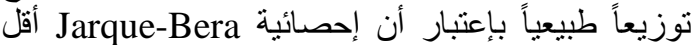

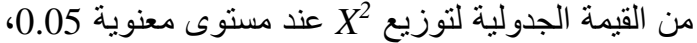

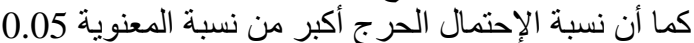

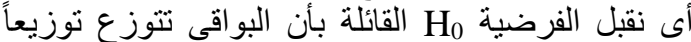

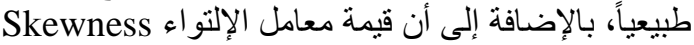
تدل على تماثل وتناظر التوزيع الإحتمالى للبواقى التىجدول
يؤدي ذلك الى إرتفاع رصيد الميزان الزراعى بنسبة

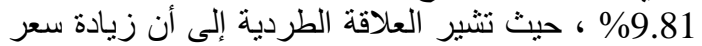

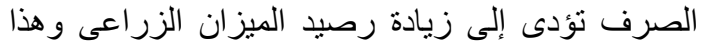

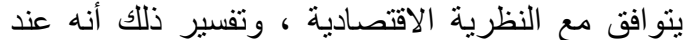

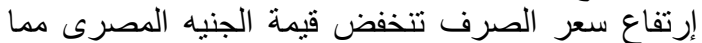
يؤُدى إلى إنخفاض تكاليف عناصر الإنتاج المحلية بالنسبة النية

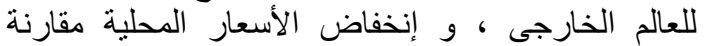

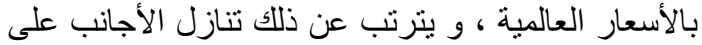

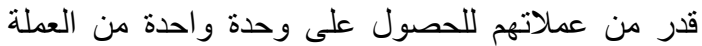

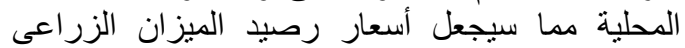

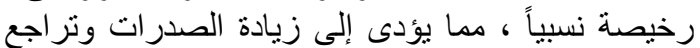

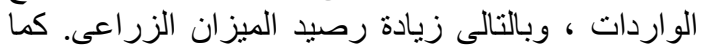
تبين النموذج عدم وجود الإرتباط الذانى بين الأخطاء لأن الني

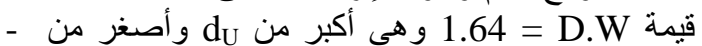
$.4 \mathrm{~d}_{\mathrm{U}}$

\section{4-اختبار استقرارية سلسلة البواقي:} بعد تمام تقدير النموذج يتم إجراء التباء اختبار استقرارية سلسلة البواقي لنموذج الصادرات الكلية بإختبار (ديكى النئ

جدول (8) : نتائج إختبار(ADF) لبو اقى النماذج المقدرة خلال الفترة (2016-2000)

\begin{tabular}{|c|c|}
\hline 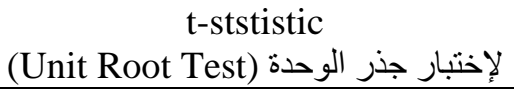 & 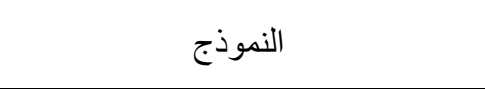 \\
\hline$-3.98^{* *}$ & سعر الصرف \\
\hline$-3.17^{* *}$ & بو اقى نموذج الصنادر ات الكلية \\
\hline$-3.40^{* *}$ & بو اقى نموذج الواردات الكلية \\
\hline$-3.79^{*}$ & بواقى نموذج الميزان التجارى الكلى \\
\hline$-3.55^{* *}$ & بو اقى نموذج الصسادر ات الزر اعية \\
\hline$-3.50^{* *}$ & بو اقى نموذج الواردات الزر اعية \\
\hline$-3.16^{* *}$ & بو اقى نموذج الميزان التجارى الزر اعى \\
\hline
\end{tabular}

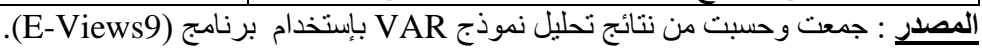

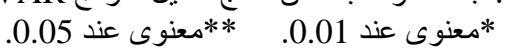

جدول (9) : نتائج إختبار التوزيع الطبيعى لبواقى نماذج التجارة الكلية والزراعية

\begin{tabular}{|c|c|c|c|c|}
\hline معامل الإلتو اء & نسبة الإحتمال الحرج & القيمة الجدولية & إحصائية Jarque-Bera & النموذج \\
\hline $0.85-$ & 0.371 & 3.841 & 1.980 & الصادر ات الكلية \\
\hline $0.914-$ & 0.318 & 3.841 & 2.288 & الواردات الكلية \\
\hline $0.797-$ & 0.389 & 3.841 & 1.888 & الميزان التجارى الكلى \\
\hline $0.729-$ & 0.465 & 3.841 & 1.530 & الصـادرات الزر اعبة \\
\hline $1.660+$ & 0.802 & 3.841 & 2.689 & الواردات الزراعية \\
\hline $1.302+$ & 0.460 & 3.841 & 0.613 & الميز ان التجارى الزر اعى \\
\hline
\end{tabular}

المصدر : جمعت وحسبت من نتائج تحليل نموذج VAR بإستخدام برنامج (E-Views9).

وبالتالي يتبين إستقر ار سلاسل بو اقى تقدير نماذج التجارة

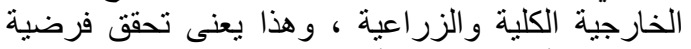

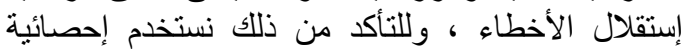

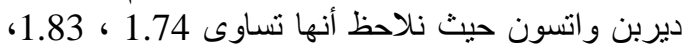

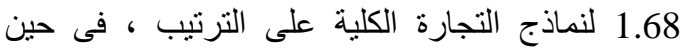
تساوى2.03، 1.64، 1.68 لنماذج التجارة الزر اعية على فئ

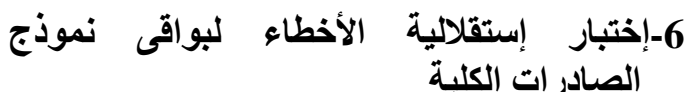

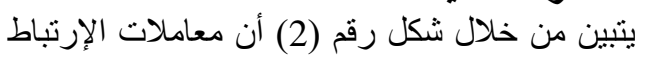

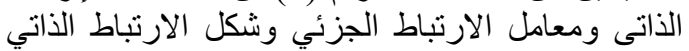

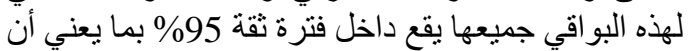

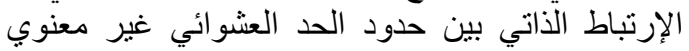


أن هنالك علاقة طردية بين سعر الصرف والصادرات

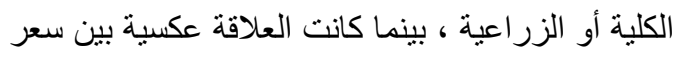

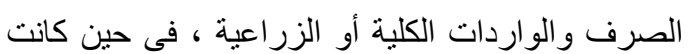

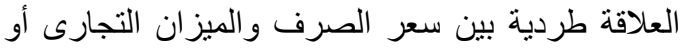

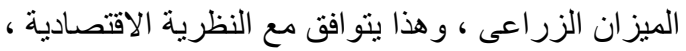

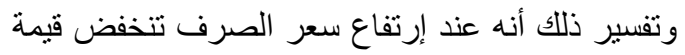
الجنيه المصرى و يؤدى إلى إنخفاض تكاليف عناصر الإنتاج المحلية بالنسبة للعالم الخارجى ، مما يؤدى إلى لئى

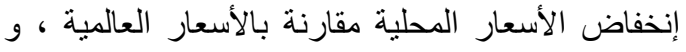
يترتب عن ذللك تنازل الأجانب على قدر من عملاتهم

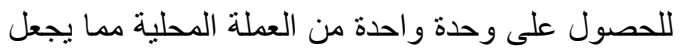
أسعار رصيد الميزان التجارى أو الزر اعى رخيصة نسبياً

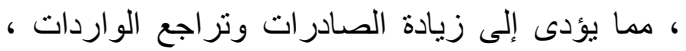
وبالتالى زيادة أرصيد الميزان التجارى و الزراعى.

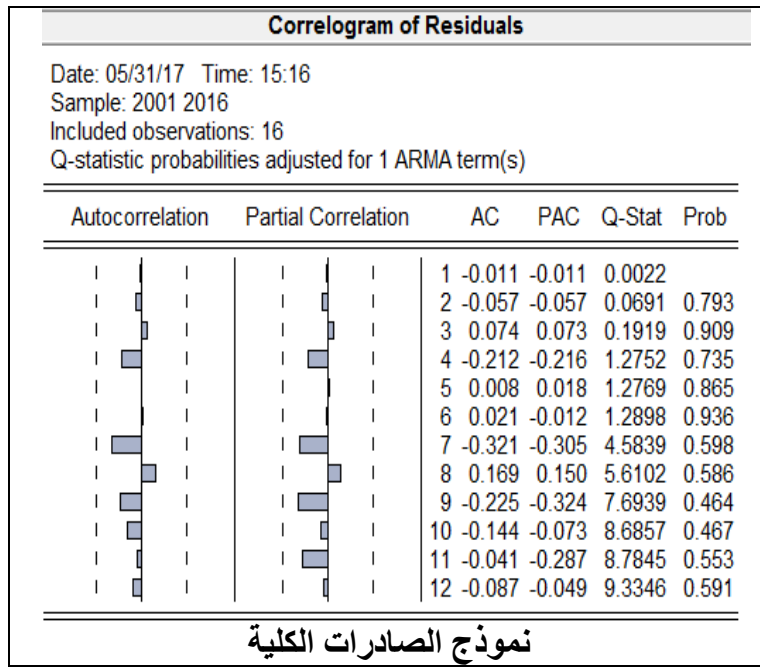

الترتيب حيث تقع فى منطقة قبول الفرضية H أى أن فرضية إستقلال الأخطاء محققة لجميع النماذج.

7-إختبار تجانس التباين لبواقى نماذج التجارة الخارجية الكلية والزراعية التئية

يتبين من خلال شكل رقم (3) أن معاملات الإرتباط التباط

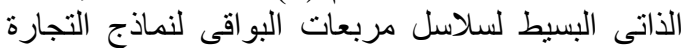

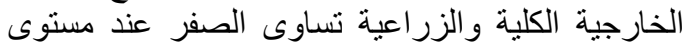

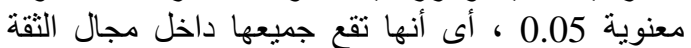

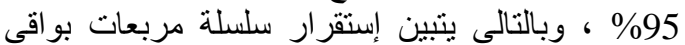

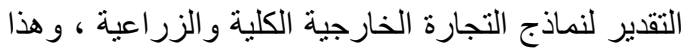
يعنى تحقق فرضية تجانس التباين الثرطى للأخطاء

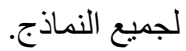

ونستنتج من دراسة التقدير القياسى لنموذج أثر تغير

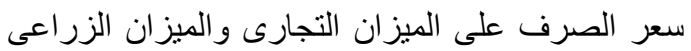
خلال الفترة (2016-2000) ، من خلال التقدير القياسى التئي لطريقة التكامل المتزامن لإختبار وجود العلاقة السبيية طويلة المدى بين سعر صرف الجنيه المصرى مقابل الدولار الأمريكى ، ورصيد الميزان التجارى والزراعى خلال الفترة (2016-2000) ، كما تبين من نتائج الدر اسة الدة الدراعي

\begin{tabular}{|c|c|c|c|c|c|c|}
\hline \multicolumn{7}{|c|}{ Correlogram of Residuals } \\
\hline \multicolumn{7}{|c|}{$\begin{array}{l}\text { Date: } 05 / 31 / 17 \text { Time: } 15: 17 \\
\text { Sample: } 20012016 \\
\text { Included observations: } 16 \\
\text { Q-statistic probabilities adjusted for } 1 \text { ARMA term(s) }\end{array}$} \\
\hline Autocorrelation & Partial Corr & lation & $A C$ & PAC & Q-Stat & Prob \\
\hline 1 & 1 & 1 & 10.009 & 0.009 & 0.0016 & \\
\hline 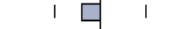 & $1 \square$ & 1 & $2-0.198$ & -0.198 & 0.8056 & 0.369 \\
\hline 1 드. & $1 \square$ & 1 & $3-0.148$ & -0.150 & 1.2882 & 0.525 \\
\hline । $\sqsupseteq$ । & & I & $\begin{array}{ll}4 & 0.200\end{array}$ & 0.170 & 2.2442 & 0.523 \\
\hline $1 \square$ & $1 \square$ & । & $5-0.260$ & -0.346 & 4.0111 & 0.405 \\
\hline $1 \square$ & $\square$ & 1 & $6-0.422$ & -0.442 & 9.1378 & 0.104 \\
\hline 1 & 1 & 1 & $7 \quad 0.056$ & -0.009 & 9.2369 & 0.161 \\
\hline$\square \quad$ । & 15 & 1 & $\begin{array}{ll}8 & 0.161\end{array}$ & -0.184 & 10.166 & 0.179 \\
\hline 1 & 1 다 & 1 & $9-0.003$ & -0.158 & 10.166 & 0.254 \\
\hline 4 & 10 & 1 & $10-0.106$ & -0.113 & 10.701 & 0.297 \\
\hline 曰 1 & 15 & 1 & 110.180 & -0.186 & 12.568 & 0.249 \\
\hline । $\quad \square \quad$ । & 1 디 & 1 & 120.164 & -0.139 & 14.494 & 0.207 \\
\hline
\end{tabular}


M. E. Mohamed

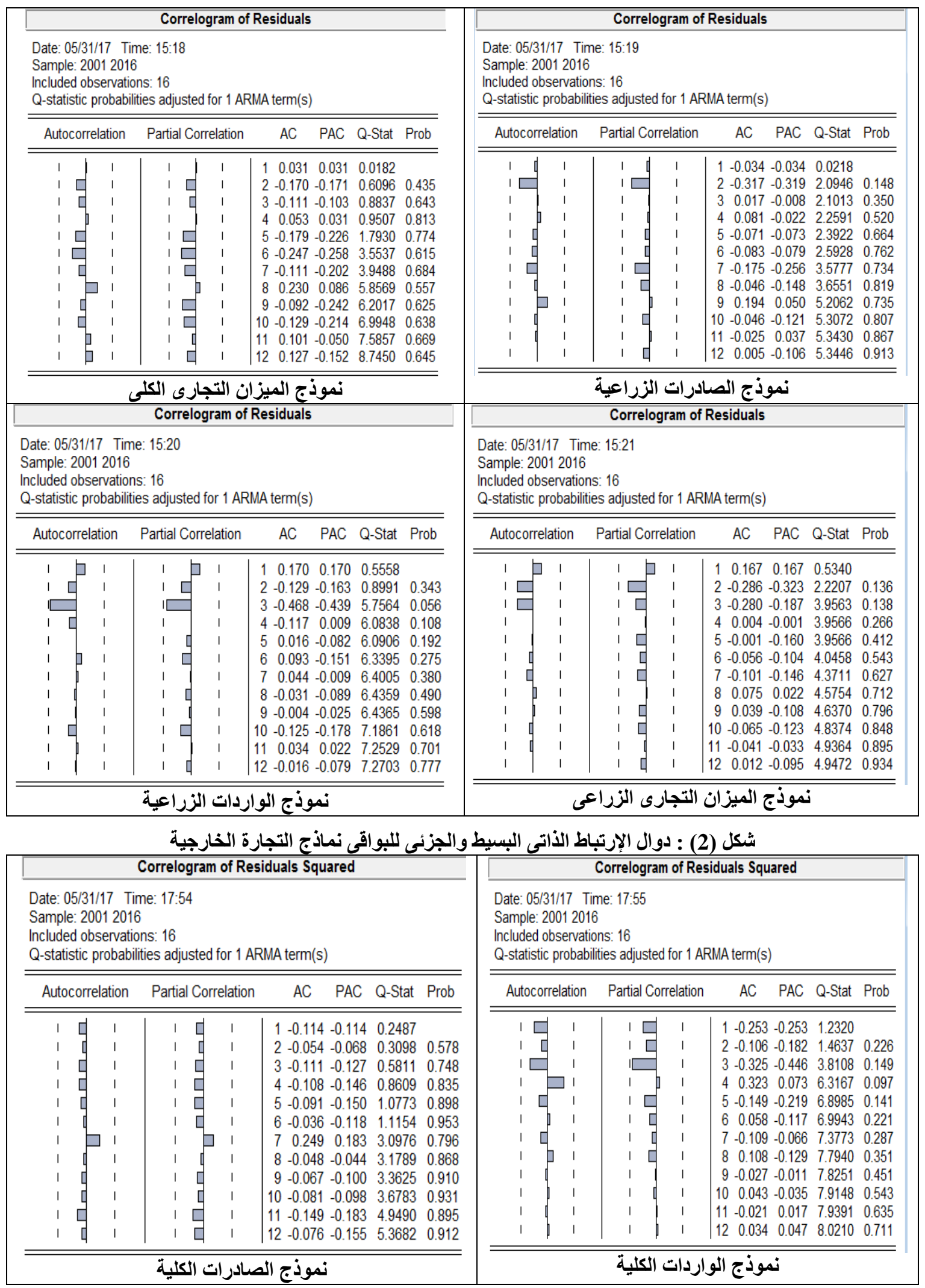


Effect of Exchange Rate Change on Total Foreign and Agricultural Trade

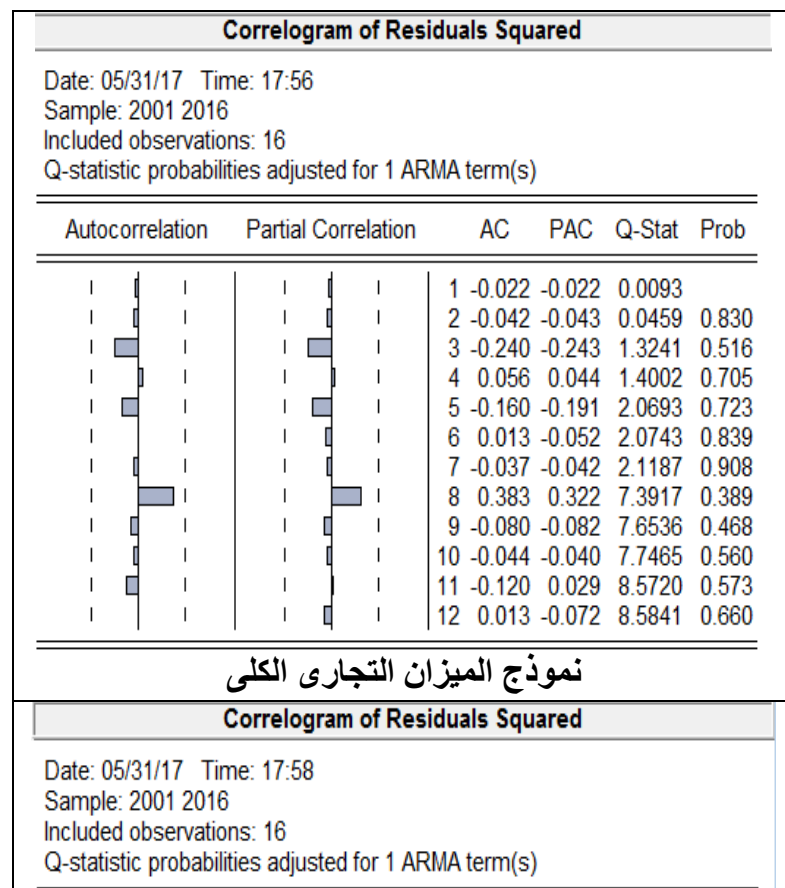

\begin{tabular}{|c|c|c|c|c|c|c|}
\hline \multicolumn{7}{|c|}{ Correlogram of Residuals Squared } \\
\hline \multicolumn{7}{|c|}{$\begin{array}{l}\text { Date: } 05 / 31 / 17 \text { Time: } 17: 57 \\
\text { Sample: } 20012016 \\
\text { Included observations: } 16 \\
\text { Q-statistic probabilities adjusted for } 1 \text { ARMA term(s) }\end{array}$} \\
\hline Autocorrelation & \multicolumn{2}{|c|}{ Partial Correlation } & \multirow{2}{*}{$\frac{A C}{1-0.226}$} & PAC & Q-Stat & Prob \\
\hline $1 \square$ & । $\square$ & । & & -0.226 & 0.9800 & \\
\hline 1 & 17 & 1 & 20.135 & 0.089 & 1.3565 & 0.244 \\
\hline । $\square$ । & & 1 & 30.281 & 0.350 & 3.1083 & 0.211 \\
\hline $1 \square 1$ & $1 \square$ & 1 & $4-0.279$ & -0.188 & 4.9773 & 0.173 \\
\hline 10 & $1 \square$ & 1 & $5-0.107$ & -0.367 & 5.2782 & 0.260 \\
\hline 1 & $1 \square$ & 1 & $6-0.088$ & -0.266 & 5.4999 & 0.358 \\
\hline $1 \square$ & 1 & 1 & $7-0.176$ & -0.002 & 6.4863 & 0.371 \\
\hline 1 & 1 & 1 & $8-0.168$ & -0.073 & 7.5074 & 0.378 \\
\hline 1 & 4 & 1 & 90.007 & -0.072 & 7.5094 & 0.483 \\
\hline 1 & โ & 1 & $10-0.033$ & -0.068 & 7.5627 & 0.579 \\
\hline 1 & 1 & 1 & $\begin{array}{ll}11 & 0.039\end{array}$ & 0.032 & 7.6490 & 0.663 \\
\hline 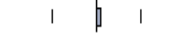 & 1 & 1 & 120.053 & -0.067 & 7.8516 & 0.727 \\
\hline \multicolumn{7}{|c|}{ نموذج الصادرات الزراعية } \\
\hline \multicolumn{7}{|c|}{ Correlogram of Residuals Squared } \\
\hline
\end{tabular}

Date: 05/31/17 Time: 17:58

Sample: 20012016

Included observations: 16

Q-statistic probabilities adjusted for 1 ARMA term(s)

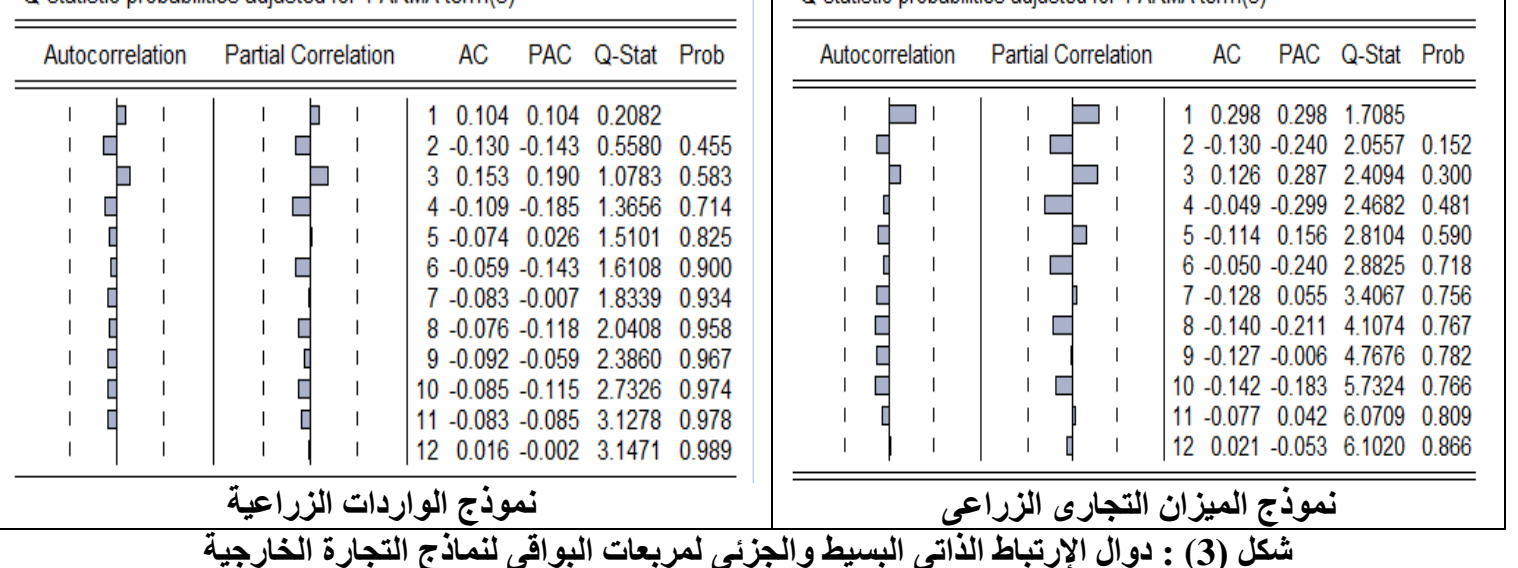

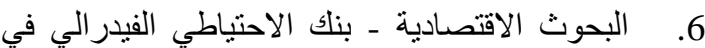

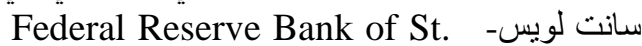

https://www.fred.stlouisfed.org Louis

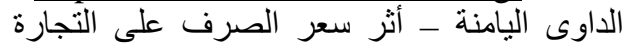

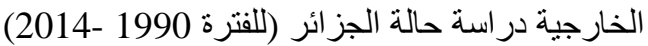
، وسالة دكتوراة ، كلية العلوم الاقتصادية و التجارية التهاية

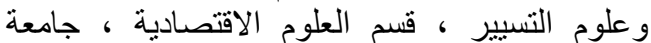

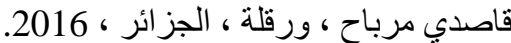

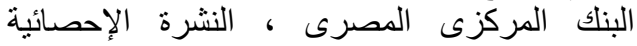

الثهرية، اعداد متفرقة .

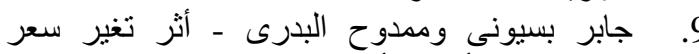

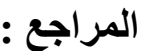

1. الموقع الإلكترونى للابنك المركزى الدصرى

www.cbe.org.eg

2. الموقع الإلكترونى للجهاز المركزى للتعبئة العامة

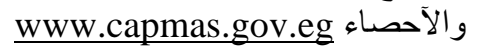

3. الموقع الإلكترونى للمنظمة العربية للتنمية الزراعية

www.aoad.org

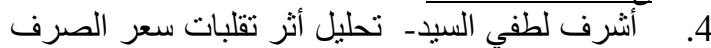

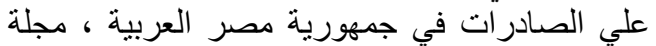

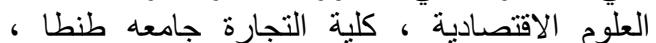

2012

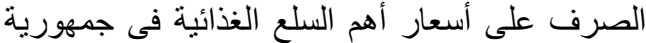

مصر العربية فى ظل الأزمة الاقتصادية العالمية العية " -

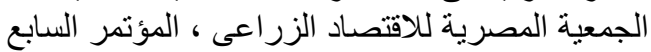

عشر للإقتصاديين الزراعيين ، الفترة من 14 - 15

أكتوبر 2009.

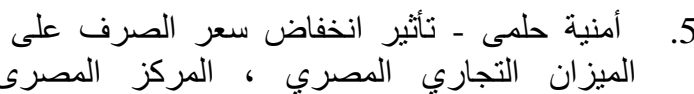

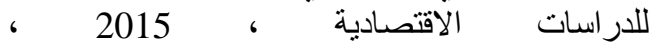

.www.eces.org.eg

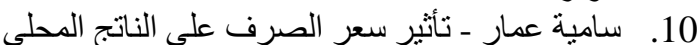

الإجمالي في الاقتصاد المصري ، الثرفير ، مجلة النهضة، كلية 
Change on the Price of the Most Important Vegetable Crops in Egypt"Third International Conference on Advances in Social Science, Economics and Management (SEM 2015), UK .Birmingham, 26-27/5/2015.

16. Gaber Bassyouni, Food gap and food security of sugar in Egypt, Igls Forum on System Dynamics and Innovation in Food Networks, February 9-13, 2015' Igls, Austria.

17. Gaber Bassyouni,Egyptian food security of edible oils, Igls Forum on System Dynamics and Innovation in Food Networks, February 13-17, 2017, Igls, Austria.

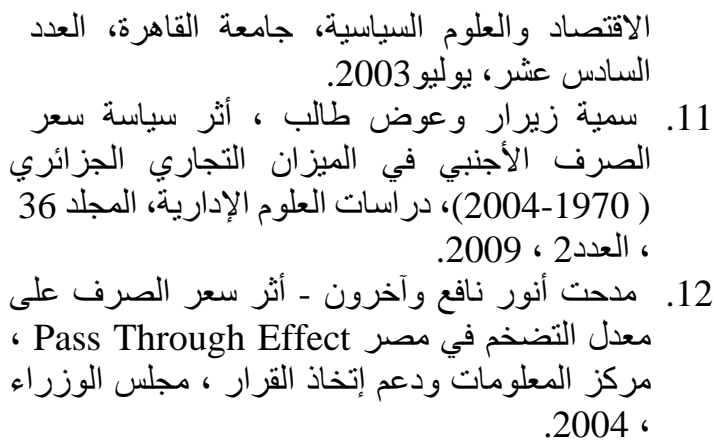

13. http://www.syrianef.org/?p=4919

14. http://www.syrianef.org/?p=491//ar. wikip edia.org/wiki قتصاد_مصر/2p

15. Ryad Ismaiel Mostafa, Mamdouh Elbadry-The Effect of Exchange Rate

\title{
EFFECT OF EXCHANGE RATE CHANGE ON TOTAL FOREIGN AND AGRICULTURAL TRADE IN EGYPT
}

\author{
M. E. Mohamed \\ Researcher - Agricultural Economics Research Institute \\ mamdouhelbadry2000@yahoo.com
}

\begin{abstract}
The study examines the effect of the change in the exchange rate of the dollar against the pound on total foreign and agricultural trade in Egypt, by measuring the efficiency of the total foreign and agricultural trade during the period 2000-2016, and design a model to measure the impact of exchange rate change on total and agricultural foreign trade in Egypt.

The results of estimation of the exchange rate effect model showed a positive relationship between the exchange rate as a dependent variable, the total exports and the balance of the total trade balance, the agricultural exports and the balance of the agricultural trade balance, separately as independent variables, while the inverse relationship between the exchange rate as a variable dependent, and both total imports and agricultural imports separately as independent variables.

The study recommends:

1- The devaluation of the Egyptian pound should not be repeated for several years, so as not to lose the confidence of foreign and local investors in the currency of the Egyptian pound.

2 - When the decision to devalue the Egyptian pound, it is necessary to return again to the old exchange rate, after the disappearance of the crisis, so as not to weaken the value of the Egyptian pound.

3 - The rate of reduction in the value of the Egyptian pound should be gradually reduced. The effects of the reduction should be calculated so as not to cause negative effects that may weaken the national economy.

4 - Need to assess the exchange rate of the Egyptian pound, against other foreign currencies, or trade exchange countries (Europe, Asia and China), not only the US dollar.
\end{abstract}


5 - It is proposed to reduce the deficit in the balance of trade balance, the need to raise interest rates on Egyptian deposits, and rationalize imports to reduce the demand for the dollar and the balance of other foreign currencies.

Key words: Exchange rate, Total exports and imports, Agricultural exports and imports, Total Trade Balance, Agricultural Trade Balance, Partial Correlation, Causality relationship, Normal Distribution, Residual of Model. 